\author{
UNIVERSIDADE DE SÃO PAULO \\ FFCLRP - DEPARTAMENTO DE BIOLOGIA \\ PROGRAMA DE PÓS-GRADUAÇÃO EM ENTOMOLOGIA
}

\title{
Revisão e análise filogenética do gênero Allominettia Hendel, 1925 (Diptera: Lauxaniidae)
}

\section{LIVIA MARIA FRARE}

Dissertação apresentada à Faculdade de Filosofia, Ciências e Letras de Ribeirão Preto da USP, como parte das exigências para a obtenção do título de Mestre em Ciências, Área: ENTOMOLOGIA

RIBEIRÃO PRETO-SP 


\author{
UNIVERSIDADE DE SÃO PAULO \\ FFCLRP - DEPARTAMENTO DE BIOLOGIA \\ PROGRAMA DE PÓS-GRADUAÇÃO EM ENTOMOLOGIA
}

\title{
Revisão e análise filogenética do gênero \\ Allominettia Hendel, 1925 (Diptera: Lauxaniidae)
}

\author{
LIVIA MARIA FRARE
}

Orientadora: Vera Cristina Silva

Dissertação apresentada à Faculdade de Filosofia, Ciências e Letras de Ribeirão Preto da USP, como parte das exigências para a obtenção do título de Mestre em Ciências, Área: ENTOMOLOGIA

RIBEIRÃO PRETO-SP

2018 
Autorizo a reprodução e divulgação total ou parcial deste trabalho, por qualquer meio convencional ou eletrônico, para fins de estudo e pesquisa, desde que citada a fonte.

\section{FICHA CATALOGRÁFICA}

Frare, Livia Maria

Revisão e análise filogenética do gênero Allominettia Hendel, 1925 (Diptera: Lauxaniidae). Ribeirão Preto, 2018. 49 p.

Orientadora: Vera Cristina Silva

Dissertação apresentada à Faculdade de Filosofia, Ciências e Letras de Ribeirão Preto da USP, como parte das exigências para a obtenção do título de Mestre em Ciências, Área: Entomologia 
Nome: Frare, Livia Maria

Título: Revisão e análise filogenética do gênero Allominettia Hendel, 1925 (Diptera: Lauxaniidae).

Dissertação apresentada à Faculdade de Filosofia, Ciências e Letras de Ribeirão Preto- USP, como parte das exigências para obtenção do título de Mestre em Ciências - Área: Entomologia.

Aprovado em:

Banca Examinadora Prof (a). Dr (a):

Instituição:

Parecer:

Assinatura:

Prof (a). Dr (a):

Instituição:

Parecer:

Assinatura:

Prof (a). Dr (a):

Instituição:

Parecer:

Assinatura:

Ribeirão Preto, de de 2018 . 
Dedico

aos meus pais Luiz Antônio e Fátima, pelo total apoio e paciência para a realização dos meus estudos. 


\section{AGRADECIMENTOS}

Agradeço a minha orientadora, Vera Cristina Silva, pelos seis anos de ensinamentos e estudos. Pela oportunidade, confiança e amizade.

Sou muito grata à minha família pelo total incentivo para que eu continuasse os meus estudos, mesmo quando os caminhos pareciam difíceis. À minha irmã, que ama falar a palavra Diptera para seus alunos e ao meu irmão que sempre está ao meu lado.

Agradeço enormemente ao Professor Dalton de Souza Amorim, por me acolher em seu laboratório e pelo acompanhamento em meus estudos.

À Bel (Maria Isabel Balbi), por me auxiliar a todo momento em minha mudança para o laboratório do Professor Dalton.

Agradeço ao pessoal do Laboratório de Morfologia e Evolução de Diptera, Diego Aguilar Fachin e Gabriela Pirani pelo total apoio para a finalização deste trabalho, Heloísa Fernandes Flores e Zeynab Bazyar, por me ajudarem a enriquecer o meu conhecimento pela Ordem que estudo e pela ajuda durante o desenvolvimento deste estudo. E, também, aos meus amigos Amanda Prato Silva, Rafael Carvalho, Thiago Polizei e Luana Guimarães Santos pela grande amizade além dos limites da vida acadêmica.

Agradeço também meu grande amigo Alex Antônio Ribeiro, que me acompanha desde a graduação, sempre me dando força desde o início da minha I.C. na UNESP de Jaboticabal/SP.

Aos colegas e professores do Departamento de Morfologia e Fisiologia Animal da Faculdade de Ciências Agrárias e Veterinárias UNESP de Jaboticabal/SP, no qual fiquei cinco anos.

Aos meus Professores da graduação e técnicos de laboratórios da Faculdade de Educação São Luís de Jaboticabal - SP (FESL), por terem um papel importantíssimo em minha vida.

Ao Professor Carlos José Einicker Lamas, por toda sua ajuda e paciência com os empréstimos de material do Museu de Zoologia da USP.

Ao Dr. Steve Gaimari (CDFA/USA), pela disposição em fotografar material tipo sob sua responsabilidade e prontidão em enviá-las.

Ao CNPq, pelo auxílio concedido (Processo: 130241/20164). 
Ao Departamento da Biologia e ao Programa de Pós-Graduação em Entomologia da Faculdade de Filosofia, Ciências e Letras de Ribeirão Preto.

E, por último, agradeço ao meu namorado, Luiz Roberto Paviani, por ser tão confiante e parceiro durante esses dois anos em que estamos juntos. Agradeço por estar sempre presente em todos os meus momentos. Agradeço também pela ajuda nas coletas realizadas para as disciplinas, juntamente com meu avô e meu pai. 


\section{RESUMO}

A família Lauxaniidae apresenta 1.894 espécies em 183 gêneros em todo o mundo e 367 espécies em 62 gêneros para a região Neotropical, dados que a colocam como uma das maiores famílias de dípteros acaliptrados, mas apesar disto, ainda é pouco estudada. Os adultos de Lauxaniidae são muito variáveis quanto à coloração, em geral são amarelados com marcas ou manchas escuras no corpo. As larvas são saprófagas e os adultos são encontrados em lugares úmidos e sombreados. Atualmente a família é dividida em três subfamílias, Homoneurinae, Eurychoromyinae e Lauxaniinae. Considerando a grande extensão da família, o gênero Allominettia Hendel, 1925 foi escolhido como foco deste estudo, cujos objetivos foram realizar sua revisão taxonômica e analisar as relações de parentesco entre as espécies do gênero, testando também sua monofilia. O gênero é parte da subfamília Lauxaniinae, $A$ análise das relações de parentesco entre suas espécies e o teste de sua monofilia foram realizados pela comparação com um grupo externo, composto por cinco espécies da mesma subfamília, Griphoneura triangulata Hendel, 1925, Deutominettia pulchrifrons Hendel, 1925, Chaetominettia mactans Fabricius, 1794, Sapromyza albiceps Fallén, 1820 e Minettia fasciata (Fallén, 1820) e de duas espécies de outras subfamílias, sendo Physegeniopsis albeto Gaimari e Silva, 2010, de Eurychoromyiinae e Homoneura (Homoneura) brevicornis (Kertész, 1913) de Homoneurinae. O material para o estudo foi obtido por empréstimo de museus nacionais e internacionais. As espécies de Allominettia foram identificadas, sendo redescritas aquelas já conhecidas, incluindo o maior número possível de características, podendo-se assim ampliar a descrição anterior, e as novas, descritas. Os resultados obtidos indicaram a monofilia de Allominettia apenas se Chaetominettia mactans e Deutominettia pulchrifrons estiverem incluídas em Allominettia. As análises das relações de parentesco entre as espécies do gênero resultaram em cinco árvores igualmente parcimoniosas e foi escolhida a árvore de consenso como hipótese dessas relações para as espécies de Allominettia. Os dados de morfologia acumulados durante o estudo foram utilizados para elaboração de uma chave de identificação de suas espécies.

Palavras-chave: Allominettia. Lauxaniidae. Taxonomia. Sistemática Filogenética. 


\section{Abstract}

The family Lauxaniidae is composed by 1,894 species in 183 genera worldwide and 367 species in 62 genera for the Neotropical Region, but despite being one of the largest families of acalyptrate dipterans, it is still little studied. Adults of Lauxaniidae are very variable in color, usually yellowish with dark markings or spots on the body. Larvae are saprophagous and adults are found in humid, shady places. Currently the family is divided into three subfamilies, Homoneurinae, Eurychoromyinae and Lauxaniinae. Considering the great diversity of the family, the genus Allominettia Hendel, 1925 was chosen as focus of this study, whose objective is to carry out its taxonomic revision and to analyze the phylogenentic relationships among its species, also testing its monophyly. This genus belongs to the subfamily Lauxaniinae, The analysis of the phylogenetic relationship among its species and the test of its monophyly were performed by the comparison with out group, composed of five species of the same subfamily, Griphoneura triangulata Hendel, 1925, Deutominettia pulchrifrons Hendel, 1925, Chaetominettia mactans Fabricius, 1794, Sapromyza albiceps Fallen and Minettia fasciata (Fallen) and two species from other subfamilies, Physegeniopsis albeto Gaimari and Silva, 2010, from Eurychoromyiinae and Homoneura (Homoneura) brevicornis (Kertész), from Homoneurinae. The material for the study was borrowed from national and international museums. The species of Allominettia were identified, those already known were redescribed, using the greatest possible number of characteristics, in order to enlarge previous descriptions, and the new ones, described. The results obtained indicated the monophyly of Allominettia only if Chaetominettia mactans and Deutominettia pulchrifrons are included in Allominettia. The analyzes of the phylogenetic relationship among the species of the genus resulted in five equally parsimonious trees and the consensus tree was chosen as a work hypothesis of these relations for the species of Allominettia. The morphological data accumulated during the study were used to elaborate a key to identify its species.

Key words: Allominettia. Lauxaniidae. Taxonomy. Phylogenetic Systematics. 


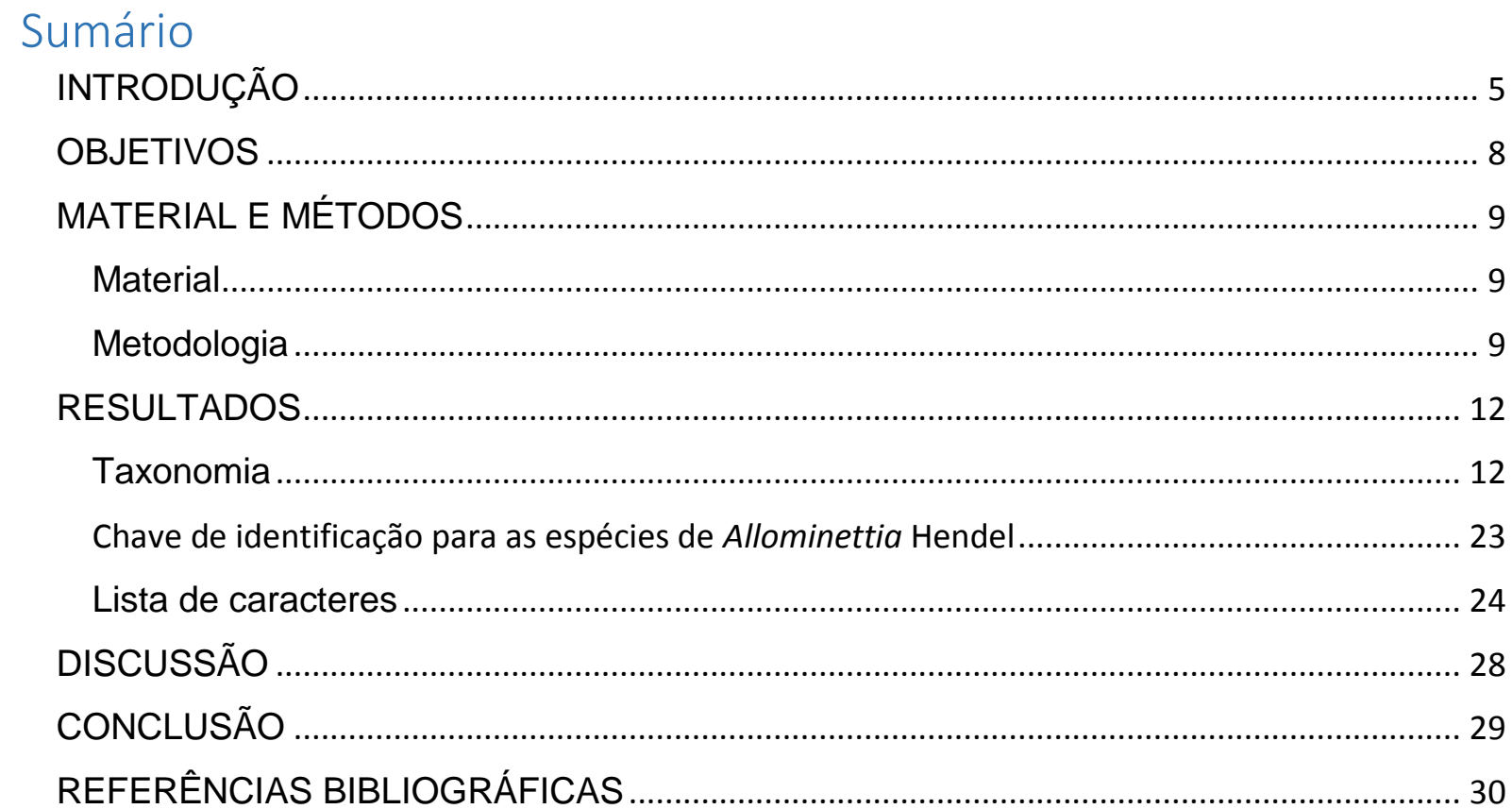




\section{LISTA DE FIGURAS}

Figura 1. Habitus, vista lateral. A. Chaetominettia mactans; B. Deutominettia pulchrifrons; C. Griphoneura triangulata; D. Physegeniopsis albeto; E. Allominettia xanthiceps; F. A. geniseta; G. A. approximata; H. $A$. sp. nov. 1 ; I. $A$. sp. nov. 2 ; J. $A$. assimilis; K. $A$. sp. nov. 3

Figura 2. Cabeça, vistas frontal e dorsal. A. Chaetominettia mactans, vista frontal; B. Deutominettia pulchrifrons, vista frontal; C. Griphoneura triangulata, vista dorsal; D. Physegeniopsis albeto, vista frontal; E. Allominettia xanthiceps, vista frontal; F. A. geniseta, vista frontal; G. A. approximata, vista dorsal; H. A. sp. nov. 1, vista frontal; I. A. sp. nov. 2, vista frontal; J. A. assimilis, vista dorsal; K. A. sp. nov. 3, vista dorsal

Figura 3. Cabeça, vista lateral. A. Chaetominettia mactans; B. Deutominettia pulchrifrons; C. Griphoneura triangulata; D. Physegeniopsis albeto; E. Allominettia xanthiceps; F. A. geniseta; G. A. approximata; H. A. sp. nov. 1; I. A. sp. nov. 2; J. A. assimilis; K. A. sp. nov. 3

Figura 4. Tórax, vista dorsal. A. Chaetominettia mactans; B. Deutominettia pulchrifrons; C. Griphoneura triangulata; D. Physegeniopsis albeto; E. Allominettia xanthiceps; F. A. geniseta; G. A. approximata; H. A. sp. nov. 1; I. A. sp. nov. 2; J. A. assimilis; K. A. sp. nov. 3

Figura 5. Asa. A. Chaetominettia mactans; B. Deutominettia pulchrifrons; C. Griphoneura triangulata; D. Physegeniopsis albeto; E. Allominettia xanthiceps; F. A. geniseta; G. A. approximata; H. $A$. sp. nov. 1 ; I. $A$. sp. nov. 2 ; J. $A$. assimilis; K. $A$. sp. nov. 3

Figura 6. Tíbia média, vista dorsolateral. A. Chaetominettia mactans; B. Deutominettia pulchrifrons; C. Griphoneura triangulata; D. Physegeniopsis albeto; E. Allominettia xanthiceps; F. A. geniseta; G. A. approximata; H. A. sp. nov. 1; I. A. sp. nov. 2; J. A. assimilis; K. A. sp. nov. 3

Figura 7. Abdome, vista dorsal. A. Chaetominettia mactans, §̊; B. Deutominettia pulchrifrons,

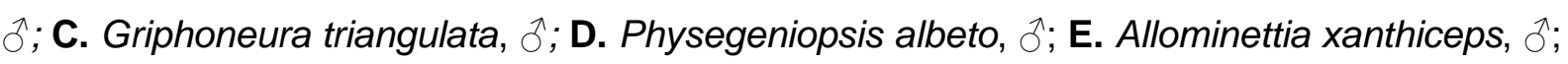

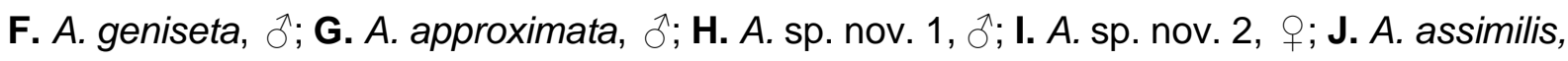

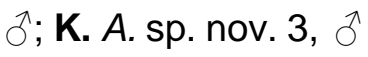

Figura 8. A. xanthiceps, terminália masculina. A. vista lateral; B. vista dorsoventral 
Figura 9. Terminália masculina, vista lateral. A. Chaetominettia mactans; B. Griphoneura triangulata; C. Deutominettia pulchrifrons; D. Allominettia xanthiceps; E. A. geniseta; F. A. approximata; G. $A$. sp. nov. 1 ; H. $A$. sp. nov. 2 ; I. $A$. assimilis; J. $A$. sp. nov. 3

Figura 10. Terminália masculina, vista dorsoventral. A. Chaetominettia mactans; B. Griphoneura triangulata; C. Deutominettia pulchrifrons; D. Allominettia xanthiceps; E. A. geniseta; F. A. approximata; G. A. sp. nov. 1 ; H. A. sp. nov. 2; I. A. assimilis; J. A. sp. nov. 3

Figura 11. Pós-abdome da fêmea e espermatecas de espécies de Lauxaniidae. A. Allominettia xanthiceps, espermateca; B. A. xanthiceps, pós-abdome, vista lateral; C. Griphoneura triangulata, espermateca; D. A. geniseta, pós-abdome, vista dorsoventral

Figura 12. Material tipo das espécies de Allominettia. A - D. A. approximata, holótipo: A., Habitus, vista lateral, B., Cabeça, vista dorsolateral C., Tórax, vista dorsal, D., Dados das etiquetas; E- H. A. assimilis, holótipo: E., Habitus, vista lateral, F., Cabeça, vista dorsolateral, G., Tórax, vista dorsal, H., Dados das etiquetas; I -L. A. geniseta, holótipo: I., Habitus, vista lateral, J., Cabeça, vista dorsolateral, L., Tórax, vista dorsal; M - O. A. xanthiceps, síntipo: M., Habitus, vista lateral, N., Asa, O., Cabeça, vista dorsolateral 45

Figura 13. A e B. Árvores resultantes da análise cladística de Allominettia, com pesagem igual. 46

Figura 14. A e B. Árvores resultantes da análise cladística de Allominettia, com pesagem igual

Figura 15. A. Árvore resultante da análise cladística de Allominettia, com pesagem igual; B. Consenso das árvores resultantes da análise cladística de Allominettia, com pesagem igual 


\section{LISTA DE TABELAS}

Tabela 1. Matriz de dados com 49 caracteres e 14 táxons terminais utilizados na análise .. 49 


\section{INTRODUÇÃO}

A família Lauxaniidae apresenta 1.894 espécies em 183 gêneros em todo o mundo (THOMPSON, 2008), e 367 espécies em 62 gêneros para a região Neotropical (CARVALHO et al. 2012), mas, apesar desta grande diversidade, a família ainda é pouco estudada (PAPP \& SILVA, 1995).

Lauxaniidae está incluída nos dípteros acaliptrados, superfamília Lauxanioidea, que inclui também Celyphidae e Chamaemyidae (GAIMARI \& SILVA, 2010a). As moscas da família Lauxaniidae apresentam o corpo pequeno à moderadamente grande, seu comprimento varia de 2 a $11 \mathrm{~mm}$. A coloração é variada - muitas apresentam manchas, marcas ou faixas (GAIMARI \& SILVA, 2010b). As larvas são saprófagas e os adultos são encontrados em lugares úmidos e sombreados (CARVALHO et al., 2012).

Atualmente, a família é dividida em três subfamílias, Homoneurinae, Eurychoromyinae e Lauxaniinae. Homoneurinae foi proposta por Stuckenberg (1971) e é caracterizada por apresentar a costa da asa homoneuriforme (as sétulas costais alcançam o ápice da veia $R_{4+5}$ ), presença de dois ou três esporões na tíbia média (McALPINE, 1989) e presença de ctenídio (STUCKENBERG, 1971). Eurychoromyinae é um pequeno grupo de espécies exclusivamente neotropicais, caracterizado por cedas escutelares fracas ou ausentes e cerdas dorsocentrais 0+2 ou 0+3 (GAIMARI \& SILVA, 2010a). Lauxaniinae é caracterizada pela ausência de todos esses caracteres e é considerada parafilética por vários autores (STUCKENBERG, 1971, SHEWEELL, 1987, PAPP \& SHATALKIN, 1998, GAIMARI \& SILVA, 2010b).

Stuckenberg (1971) revisou os gêneros de Lauxaniidae do Velho Mundo, incluindo uma chave de identificação para os gêneros, além de comentários sobre aspectos da morfologia, sistemática e biogeografia da família. Para a região Neotropical, destaca-se o capítulo sobre Lauxaniidae do Manual de Diptera da América Central (BROWN et al., 2010), que incluiu uma breve sinopse de cada gênero, além de uma chave de identificação para gêneros americanos (GAIMARI \& SILVA, 2010b).

O gênero Allominettia, descrito por Hendel (1925), está classificado dentro da subfamília Lauxaniinae e possui distribuição que abrange as regiões Neotropical e Neártica, sendo que nesta última está presente no sul dos Estados Unidos e México.

Os espécimes de Allominettia apresentam como características diagnósticas o escutelo nu; cerdas intra-alares presentes; tíbia média com cerdas posteriores curtas e fortes; asa com veias transversais marrom escuro; veia $\mathrm{CuA}_{1}$ fracamente manchada; cerdas ocelares fracas (GAIMARI \& SILVA, 2010b).

Atualmente, existem apenas duas espécies descritas para o gênero, a espécie-tipo, $A$. maculatifrons Hendel, 1925, do Peru, e A. xanthiceps (Williston, 1897), conhecida do Equador, 
Peru e Brasil. Em um trabalho em preparação, Silva e Gaimari propõem a sinonimização das duas espécies, além de outras mudanças taxonômicas que elevarão para quatro as espécies do gênero, que ficará composto por $A$. approximata (Malloch, 1928), conhecida do Panamá, Venezuela e Trindade; $A$. assimilis (Malloch, 1926), conhecida do Panamá, Colômbia, Trindade, Venezuela e Brasil; A. geniseta (Malloch, 1926), distribuída nos Estados Unidos (Texas), México, Guatemala, Costa Rica e Panamá; e A. xanthiceps (Williston, 1897), conhecida do Equador, Peru e Brasil (Silva, comum. pess.). Este estudo teve como base esses resultados.

Malloch (1926) discutiu os caracteres utilizados para agrupar espécies dentro de Lauxaniidae, como a presença da cerda intra-alar em Minettia, um dos grandes gêneros de Lauxaniidae, indicando que estudos posteriores sobre essas espécies certamente levariam a uma subdivisão do gênero. Por causa dessa visão sobre as características definidoras de Minettia, esse autor descreveu nesse gênero várias espécies consideradas por ele como "aberrantes", até que o estudo de material adicional da América do Sul ajudasse a elucidar a natureza distintiva (ou não) dos caracteres utilizados até então para esse grupo de gêneros. Desse modo, três das espécies descritas por Malloch (1926; 1928) em Minettia deverão ser incluídas em Allominettia (GAIMARI \& SILVA, 2010b; SILVA \& GAIMARI, em preparação). Isso indica a necessidade de mais estudos, que possam apresentar características morfológicas que sejam diagnósticas para esses táxons.

As relações de parentesco dentro da família foram pouco estudadas, e os dados estão restritos a poucos gêneros. Pestano e colaboradores (2003) estudaram a diversificação das espécies do gênero Sapromyza Fallén, 1820 na Ilha da Madeira, apresentando uma filogenia dessas espécies com base em dados moleculares mitocondriais. Gaimari (2004) apresentou uma hipótese das relações de parentesco entre as espécies de Evertomya, um gênero descrito nesse trabalho, mas usou como grupo externo apenas Protrigonometopus $s p$. $n$. Mello (2007) realizou a revisão e a análise cladística das espécies de Physoclypeus Hendel, 1907, mas seus dados finais apenas foram apresentados em um congresso (MELLO \& SILVA, 2008). Semelbauer (2016) fornece em seu trabalho uma análise filogenética baseada em sequências de DNA de várias espécies europeias de Lauxaniidae; seu resultado indica a não monofilia do gênero Sapromyza, algo discutido por vários autores, como Stuckenberg (1971), Merz (2007) e Gaimari e Silva (2010b). Li e colaboradores (2017) realizaram uma análise filogenética para a superfamília Lauxanioidea, utilizando dados mitocondriais; amostraram 28 espécies de dípteros, incluindo 25 braquíceros e 3 espécies de nematóceros como grupo externo. Todas essas publicações, embora sejam muito importantes, não contribuíram para esclarecer as relações de parentesco entre os gêneros de lauxaniídeos, ou mesmo confirmar 
a monofilia das subfamílias propostas. Ou seja, há a necessidade de mais análises filogenéticas, e se possível, mais abrangentes, para o esclarecimento da evolução da família.

A construção de uma hipótese das relações de parentesco entre um grupo de gêneros pode auxiliar na resolução gradual do problema da análise filogenética da família como um todo, considerando-se que, embora uma das maiores de Acalyptratae, a família Lauxaniidae não tem nenhuma hipótese de filogenia abrangente proposta na literatura. Isso gera um conhecimento que ajuda, gradualmente, a compor uma base de dados que terá enorme utilidade na proposição de uma análise filogenética da família como um todo. As dimensões da família e a grande variabilidade entre os gêneros fazem com que as revisões filogenéticas de grupos pequenos, como Allominettia, gerem uma compreensão da morfologia em clados menores dentro da família.

Até o presente, não existem revisões taxonômicas para Allominettia e não existe publicada uma chave para identificação de suas espécies. 


\section{OBJETIVOS}

Como objetivo geral este estudo buscou revisar o gênero Allominettia Hendel, 1925 (Diptera: Lauxaniidae), cujas espécies são conhecidas do Novo Mundo.

Como objetivos específicos:

- Estudar a morfologia dos adultos, em especial da terminália masculina e aprimorar a diferenciação entre as espécies;

- Redescrever o gênero e aprimorar as descrições das espécies conhecidas;

- Descrever eventuais espécies novas;

- Construir, utilizando caracteres diagnósticos relevantes, uma chave de identificação das espécies do gênero;

- Testar a monofilia do gênero;

- Considerando o gênero monofilético, elaborar uma hipótese para as relações de parentesco entre as espécies conhecidas. 


\section{MATERIAL E MÉTODOS}

Material

Durante a realização deste estudo, foram observados 113 exemplares pertencentes à Allominettia. Este trabalho teve como base o material depositado na Coleção de Diptera do Museu de Zoologia da Universidade de São Paulo. Além disso, utilizou-se também de material obtido por empréstimo de outras instituições nacionais e internacionais, listadas a seguir, com indicação de suas acronímias: Coleção Zoológica do Maranhão, do Centro de Estudos Superiores da Universidade Estadual do Maranhão, Caxias (CZMA); Departamento de Zoologia da Universidade Federal do Paraná, Curitiba (DZUFPR); Instituto Nacional de Pesquisas da Amazônia, Manaus (INPA); Museu Nacional da Universidade Federal do Rio de Janeiro, Rio de Janeiro (MNRJ); "National Museum of Natural History", Washington, D. C. (USNM); "The American Museum of Natural History", Nova lorque (AMNH); e "The Natural History Museum", Londres (BMNH). Além disso, tivemos acesso a material recebido por empréstimo anteriormente, pela orientadora deste estudo, e que se encontrava em nosso laboratório, como exemplares das coleções do Instituto de Investigación de Recursos Biológicos Alexander von Humboldt", Bogotá, Colômbia (IAvH-E); "Bohart Museum of Entomology", University of California, Davis (UCD) e "Lund Museum of Zoology", Lund, Suécia (MZLU). O material tipo foi obtido a partir do envio de fotografias da USNM (Fig. 12A-O).

\section{Metodologia}

Análise taxonômica

O estudo morfológico foi realizado com exemplares secos (alfinetados) ou úmidos (preservados em álcool 70\%; $80 \%$ ou 95\%). A metodologia empregada é a usual em estudos sistemáticos de dípteros: observação e desenho ao microscópio estereoscópico de estruturas maiores, e dissecção do material, montagem de lâminas para exame ao microscópio óptico e execução de desenhos, com auxílio de câmara-clara, para estruturas menores. Estruturas de interesse taxonômico foram fotografadas em diferentes focos e, posteriormente, foram editadas através de um programa de montagem de fotos.

Os exemplares selecionados para estudo das terminálias tiveram a parte posterior do abdome removida e inserida em solução de $\mathrm{KOH}$ a $10 \%$, durante o tempo necessário para remoção das estruturas musculares e membranosas, em geral de 15 a 20 minutos, com observação constante; após essa etapa, o material foi inserido em água destilada, para remoção do $\mathrm{KOH}$, mantido em ácido acético glacial por 30 minutos para neutralização do $\mathrm{KOH}$ e, posteriormente, desidratado em uma série alcoólica de concentrações crescentes (30\%, 
$50 \%, 70 \%$ e $92 \%$ ); finalizada a série alcoólica, as terminálias foram removidas das demais partes do abdome, mantidas em lactofenol para clareamento e montadas em lâminas contendo glicerina. Após descrição e ilustração das terminálias, o material foi acondicionado em tubos para genitália contendo glicerina e alfinetados juntos aos seus respectivos exemplares. As asas foram removidas e colocadas em lacto-fenol por alguns minutos para limpeza, montadas em lâminas com glicerina, fotografadas em microscópio com câmera acoplada e guardadas nos tubetes citados anteriormente, alfinetados junto com os exemplares.

O material foi fotografado em microscópio com câmera acoplada e as fotos foram editadas no programa Ellicon focus 6.0; as edições foram feitas através do programa Photoshop.

A terminologia morfológica segue Cumming \& Wood (2009) e Gaimari \& Silva (2010b). A figura 8 foi incluída como um modelo, apresentando legendas para as estruturas da terminália masculina citadas neste estudo; o mesmo foi feito na figura 11, para a terminália feminina.

$\mathrm{Na}$ descrição do gênero procurou-se apresentar o maior número possível de características de tal modo que na descrição das espécies foram citados apenas os aspectos em que cada táxon difere dessa descrição geral.

Na indicação da distribuição das espécies, optou-se por listar as localidades do norte para o sul e de leste para oeste.

\section{Análise filogenética}

O estudo das relações filogenéticas entre as espécies de Allominettia foi feito utilizandose a metodologia cladística (HENNIG 1966; KITCHING et al. 1998; SCHUH 2000; AMORIM 2002). Utilizou-se caracteres morfológicos e a análise foi conduzida, segundo o princípio da parcimônia, no programa TNT (GOLOBOFF et al., 2008), com os seguintes parâmetros: random seed $=0$, hold $=99$ 999, hold/45 em um tbr de 900 replicações. A matriz de caracteres foi construída no programa Winclada ver. 1.00.08 (NIXON, 2002) e conta com 49 caracteres. Os procedimentos das séries de transformação foram feitos a posteriori, por meio da comparação e enraizamento com grupo externo (NIXON \& CARPENTER, 1993). Todos os caracteres foram tratados como não-ordenados. Os dados ausentes foram tratados como (?).

A amostragem compreende 14 táxons terminais correspondentes a oito gêneros. O grupo interno é representado por 7 táxons terminais (sendo quatro espécies conhecidas e três novas espécies de Allominettia) e o grupo externo por 7 táxons terminais (seis espécies conhecidas de Lauxaniidae).

Como grupo externo, foram utilizadas cinco espécies de gêneros da subfamília Lauxaniinae: Chaetominettia mactans (Fabricius, 1794), Griphoneura triangulata (Hendel, 1925), Sapromyza albiceps Fallén, 1820, Minettia fasciata (Fallén, 1820) e Deutominettia 
pulchrifrons (Hendel, 1925); e das outras subfamílias, Physegeniopsis albeto Gaimari e Silva, 2010, pertencente a Eurychoromyiinae, e Homoneura (Homoneura) brevicornis (Kertész, 1913), pertencente a Homoneurinae.

Os dados das espécies do grupo interno e algumas do grupo externo como Physegeniopsis albeto, Griphoneura triangulata e Deutominettia pulchrifrons foram obtidos de exame de exemplares e para Minettia fasciata, Homoneura brevicornis e Sapromyza albiceps da literatura: Collin (1948), Remm \& Elberg (1979), Merz (2004), Shi et al. (2012) e Lee \& Han (2015), e também fotografias identificadas por especialistas, em sites reconhecidos, como "Bugguide" e "Discover Life". 


\section{RESULTADOS}

Como resultado final, todas as espécies conhecidas foram redescritas e 3 novas espécies foram descritas, totalizando 7 espécies válidas para o gênero Allominettia.

\section{Taxonomia}

\section{Allominettia Hendel, 1925}

Allominettia Hendel, 1925: 126. Espécie tipo, A. maculatifrons Hendel (des. orig.) = xanthiceps Williston.

Diagnose: escutelo nu; cerdas intra-alares presentes; tíbia média com cerdas posteriores curtas e fortes; asa com veias transversais marrom escuro; cerdas ocelares fracas.

\section{Re-descrição.}

Cabeça: triângulo ocelar castanho, junto ao vértice e bem desenvolvido; ocelos próximos. Parafrontália com ou sem mancha. Olho arredondado, mais alto do que largo, margem posterior reta. Antena: escapo menor que pedicelo; cerdas na base do pedicelo, curtas e fortes; primeiro flagelômero oval, ápice arredondado, comprimento cerca de 2,5X a largura basal; arista plumosa, cerdas maiores na base e menores no ápice; arista mais longa que o flagelômero. Quetotaxia: cerdas pós-ocelares convergentes; cerdas fronto-orbitais reclinadas, cerda anterior cerca de 1/3 do tamanho da posterior, distância da cerda frontoorbital anterior em relação à margem ocular igual ou menor comparativamente à essa medida para a cerda fronto-orbital posterior (isto é, as linhas imaginárias unindo as bases das cerdas fronto-orbitais anteriores e posteriores formam a figura de um retângulo, no caso da distância ser igual, ou um trapézio, no caso da distância ser menor); cerda vertical interna longa, 1,5x maior que a cerda vertical externa; cerdas ocelares divergentes e fracas; cerdas supravibrissais longas ou curtas.

Tórax: escutelo curto, achatado, mais largo do que longo. Quetotaxia: 0+3 cerdas dorsocentrais; 1 cerda acrostical; 1 cerda pós pronotal; 1 cerda intra-alar presente e bem desenvolvida ou fracamente desenvolvida; 1 cerda supra-alar pré-sutural; 2 cerdas supraalares pós-sutural; 2 cerdas notopleurais; 1 cerda anepisternal; anepímero nu; 1-2 cerdas catepisternais; 2 cerdas escutelares, apicais variáveis. Pernas - quetotaxia: coxa anterior, 3 cerdas apicais; fêmur anterior com 2 fileiras de cerdas posteriores, 1 fileira ventral de cerdas; tíbia anterior, 1 cerda apical dorsal, 1 cerda apical ventral; coxa média, 4 cerdas apicais; fêmur 
médio, 1 fileira ventral de cerdas, 1 fileira de cerdas posteriores; tíbia média, de 2 a 4 esporões apicais ventrais, e de 3 a 7 cerdas antero-dorsais; coxa posterior, 2 cerdas apicais; fêmur posterior, 1 fileira de cerdas posteriores, 1 esporão apical; tíbia posterior, 1 cerda apical dorsal, 1 cerda apical ventral. Asa: hialina, amarelada, com manchas marrons nas veias transversais dm-cu e r-m; costa amplamente ou levemente marrom.

Abdome: coloração amarelada, com ou sem borda escura nos tergitos; formato cônico nas fêmeas; macho com abdome estreito; sintergitos 1+2 fundidos; tergitos com cerdas curtas e fortes; esternitos com pelos.

Terminália masculina: sintergoesternito 7-8 simples, em forma de sela. Epândrio apresentando muitas cerdas. Surstilo articulado com o epândrio. Cerco simples, arredondado, apresentando muitas cerdas. Falo com espinhos internos dispostos longitudinalmente, em vistas lateral e dorsoventral. Hipândrio com presença de lobos direcionados posteriormente.

Terminália feminina: esternito 7 formando anel incompleto, com cerdas finas, espiráculo presente lateralmente. Tergito 8 mais largo do que longo. Esternito 8 mais largo do que longo, em forma de escudo; cerdas finas. Epiprocto simples, semicircular, com cerdas. Hipoprocto alongado, com cerdas longas, algumas fortes e outras fracas. Cerco simples, alongado, com muitas cerdas. Espermatecas com configuração 2+1, esféricas; superfícies lisas e ligadas ao duto; ápice de ambos os dutos sem esclerotização.

Lista das espécies do gênero: $A$. approximata (Malloch, 1928), A. assimilis (Malloch, 1926), A. geniseta (Malloch, 1926), A. xanthiceps (Williston, 1897), A. sp. nov. 1, A. sp. nov. 2 e $A$. sp. nov. 3.

\section{Allominettia approximata (Malloch, 1928)}

(Figs. 1G, 2G, 3G, 4G, 5G, 6G, 7G, 9F, 10F,12 A-D)

Allominettia approximata (Malloch, 1928: 3; Deutominettia). Localidade-tipo: Panamá, Rio Trinidad. Holótipo macho, n40 965, USNM.

Diagnose: parafrontália sem mancha; tíbia média com 7 cerdas ântero-dorsais; asa com costa amplamente marrom; veia $\mathrm{CuA}_{2}$ sem manchas.

\section{Re-descrição.}


Cabeça (Figs. 2G, 3G): vértice arredondado. Fronte amarela; parafrontália sem mancha; ângulo fronto-facial $90^{\circ}$; perfil convexo. Face convexa; margem bucal ampla. Parafácia e gena relativamente largas; gena com cerda longa abaixo da face, marrom. Olho arredondado, mais alto do que largo, margem posterior reta. Antena: escapo e pedicelo amarelos; arista marrom, plumosa. Occipício amarelo. Quetotaxia: distância da cerda frontoorbital anterior em relação à margem ocular igual à essa distância para a cerda fronto-orbital posterior; cerdas supravibrissais marrons, curtas e finas.

Tórax (Fig. 4G): mesonoto castanho; pleura amarela. Quetotaxia: cerda intra-alar presente, fracamente desenvolvida; 1 cerda catepisternal; cerdas escutelares apicais divergentes. Pernas: amareladas. Quetotaxia: coxa média, 4 cerdas apicais; tíbia média, 4 esporões apicais ventrais, 7 cerdas anterodorsais (Fig. 6G). Asa (Fig. 5G): hialina, amarelada, com manchas marrons nas veias transversais dm-cu e r-m; costa sem mancha marrom; região do ápice de $R_{2+3}$ e até o ápice de $M_{1}$ sem manchas; $C u A_{2}$ sem manchas; CuA+CuP curta; lóbulo anal com $A_{1} 2 x$ mais longa que $\mathrm{CuA}+\mathrm{CuP}$. Halter amarelo.

Abdome (Fig. 7G): coloração amarelada sem borda escura (marrom) nos tergitos.

Terminália masculina (Figs. 9F, 10F): sintergoesternito 7-8 simples, em forma de sela. Epândrio em vista lateral, estreito anteriormente e largo posteriormente; extremidade, apresentando muitas cerdas. Surstilo articulado com o epândrio, levemente esclerotizado, superfícies dorsal e dorsolateral com cerdas. Falo com espinhos internos dispostos longitudinalmente em vistas lateral e dorsoventral, ápice do falo em vista lateral bifurcado, voltado internamente; base do falo sem abaulamento. Hipândrio com parte mediana muito estreita e presença de lobos direcionados posteriormente. Pósgonito com projeção digitiforme. Falapódema cerca de 0,5X o tamanho relativo do falo. Apódema ejaculatório largo, localizado dorsoventralmente na região central.

Terminália feminina (como na Fig. 11A-D): Idem descrição do gênero.

Distribuição: Panamá, Venezuela, Trinidad e Colômbia (Magdalena).

Material estudado: TRINIDAD. W.I. Bianchisseuse. On Piperaceae bushes nr. Marianne River bridge, 10-I-92, C. Michalski, 1 (AMNH). ST. ANNS, 15.viii.19331q (AMNH).

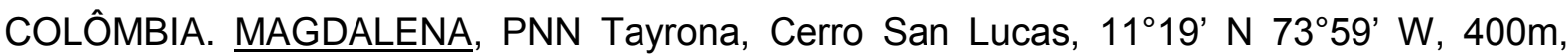
Malaise, 06.01.2003-11.01.2003, C. Sarmiento Leg.3431, 1 q (IAvH-E); idem, 11ํ19' N 7359' W, 500m, Malaise, 11.01.2003 16/01/2003, C. Sarmiento Leg. M. 3427, 1 + (IAvH-E); idem, $11^{\circ} 19^{\prime}$ N 735' W, 600m, Malaise, 06.01.2003-11.01.2003, C. Sarmiento Leg.3429, 5 ㅇ

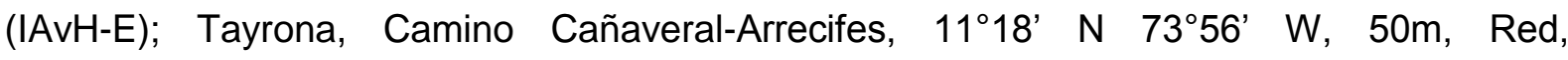
21.07.2002-23.07.2002, M. Sharkey, D. Arias \& E. Torres Leg. M. 4172, 6 §, 6 q (IAvH-E); 
Tayrona, Cerro San Lucas, 1119' N 7359' W, 550m, Malaise 2, 11.01.2003-16.01.2003, C. Sarmiento Leg. M. 3426, 2 ㅇ, $7 \overbrace{}^{\Uparrow}(\mathrm{IAvH}-\mathrm{E})$; Bolivar, SFF Los Colorados, Alto el Mirador, $9^{\circ} 54^{\prime}$ N 75ㄱ' W, 400m, Malaise, 06.10.2001-24.10.2001, E. Deulufeut Leg. M. 2417, $1 \delta^{\Uparrow}$ (IAvH-E).

\section{Allominettia assimilis (Malloch, 1926)}

(Figs. 1J, 2J, 3J, 4J, 5J, 6J, 7J, 9I, 10I, $12 \mathrm{E}-\mathrm{H}$ )

Allominettia assimilis (Malloch, 1926: 17; Minettia). Localidade tipo: Panamá, Canal Zone, Gatún Lake, Cano Saddle. Holótipo macho, n²8 452, USNM.

Diagnose: parafrontália sem mancha; tíbia média com 3 cerdas anterodorsais; asa com costa amplamente marrom; veia $\mathrm{CuA}_{2}$ sem manchas.

\section{Re-descrição.}

Cabeça (Figs. 2J, 3J): vértice arredondado. Fronte amarela; parafrontália sem mancha; ângulo fronto-facial em 90; perfil convexo. Face convexa; margem bucal ampla. Parafaciália e gena relativamente largas; gena com cerda longa abaixo da face, marrom. Olho arredondado, mais alto do que largo, margem posterior reta. Antena: escapo e pedicelo amarelos; arista marrom, plumosa. Occipício amarelo. Quetotaxia: cerdas pós-ocelares convergentes; cerdas fronto orbitais reclinadas, anterior menos que 1/3 tamanho da posterior, distância da fronto-orbital anterior em relação à margem ocular igual à distância da frontoorbital posterior; cerdas ocelares divergentes e fracas; supravibrissais longas.

Tórax (Fig. 4J): mesonoto amarelo; pleura amarela. Quetotaxia: cerda intra-alar presente e fracamente desenvolvida; 2 cerdas catepisternais; 2 cerdas escutelares, apicais divergentes. Pernas: amareladas. Quetotaxia: coxa média, 4 cerdas apicais; tíbia média, 4 esporões apicais ventrais, 3 cerdas anterodorsais (Fig. 6J). Asa (Fig. 5J): hialina, amarelada, com manchas marrons nas veias transversais dm-cu e r-m; costa sem mancha marrom; ápice de $\mathrm{R}_{2+3}$ e até o ápice de de $\mathrm{M}_{1}$ sem manchas; $\mathrm{CuA}_{2}$ sem manchas; $\mathrm{CuA}+\mathrm{CuP}$ curta; lóbulo anal com $A_{1} 2 x$ mais longa que $C u A+C u P$, fraca. Halter amarelo.

Abdome (Fig. 7J): coloração amarelada, sem borda escura (marrom) nos tergitos.

Terminália masculina (Figs. 9I, 10I): singosternito 7-8 simples, em forma de sela. Epândrio em vista lateral, estreito anteriormente e largo posteriormente, com extremidade arredondada em vista lateral, apresentando muitas cerdas. Surstilo não articulado com epândrio, levemente esclerotizado, superfícies dorsal e dorsoventral com cerdas. Cercos simples, arredondado, com cerdas. Falo com espinhos internos longitudinalmente, em vistas lateral e dorsoventral; 
ápice do falo bifurcado em vista lateral, voltado internamente; base do falo sem abaulamento. Hipândrio, em vista dorsoventral, com parte mediana larga e presença de lobos direcionados posteriormente. Pósgonito com projeção digitiforme. Falapódema cerca de 0,5X a medida relativa do falo. Apódema ejaculatório largo, localizado dorsoventralmente na região central.

Terminália feminina (como na Fig. 11A-D): Idem descrição do gênero.

Distribuição: México, Panamá, Colômbia, Trinidad, Venezuela e Brasil.

Material estudado: MÉXICO. Villa Flores, Chis. MEX., 10.iv.1962, L.A. Strange, 1 q (UCD). COLÔMBIA. META. PNN Sierra de La Macarena, Caño Curía, Parcela, $3^{\circ} 21^{\prime}$ N7356' W, 460m, Malaise, 10.x.21.xii. 2002, M. Duarte Leg. M.2979, 1 q (IAvH-E); idem, 17.i.9.ii.2003, W. Villalba Leg., M. 3532, $1 \delta^{\Uparrow}$ (IAvH-E). MAGDALENA. PNN Tayrona, Cañaveral-Arrecifes, $11^{\circ} 18^{\prime}$ N 7356' W, 50m, Red, 21/07/2002-23/07/2002, M. Sharkey, D. Arias \& E. Torres Leg. M.4172, $1 \lesssim(\mathrm{IAvH}-\mathrm{E})$. Bolivar. SFF Los Colorados, Alto el Mirador, 954' N 75² $\mathrm{W}, 400 \mathrm{~m}$, Malaise, 06.10.2001-24.10.2001, E. Deulufeut Leg., M.2417, $1 \hat{\jmath}$ (IAvH-E).

Allominettia geniseta (Malloch, 1926).

(Fig. 1F, 2F, 3F, 4F, 5F, 6F, 7F, 9E, 10E, 11D, 12 I-L)

Allominettia geniseta (Malloch, 1926: 16; Minettia). Localidade tipo: Costa Rica, San Mateo, Higuito. Holótipo fêmea, n40 965, USNM.

Diagnose: parafrontália sem mancha; tíbia média com 4 ou 5 cerdas anterodorsais; asa com costa levemente marrom; veia $\mathrm{CuA}_{2}$ sem manchas.

Re-descrição.

Cabeça (Fig. 2F, 3F): vértice arredondado. Fronte castanha amarelada; parafrontália sem mancha; ângulo fronto-facial 90'; perfil convexo. Face convexa; margem bucal ampla. Parafaciália e gena relativamente largas; gena com cerda longa abaixo da face, marrom. Olho arredondado, mais alto do que largo, margem posterior reta. Antena: escapo e pedicelo amarelos; arista marrom, plumosa. Occipício castanho claro. Quetotaxia: distância da frontoorbital anterior em relação à margem ocular igual à essa distância para a cerda fronto-orbital posterior; cerdas supravibrissais marrons, curtas e finas.

Tórax (Fig. 4F): mesonoto castanho. Quetotaxia: cerda intra-alar presente e bem desenvolvida; 2 cerdas catepisternais; 2 cerdas escutelares, apicais divergentes. Pernas: amareladas. Quetotaxia: coxa média, 5 cerdas apicais; tíbia média, 4 esporões apicais ventrais, 4 ou 5 cerdas anterodorsais (Fig. 6F); coxa posterior, 2 cerdas posteriores; fêmur 
posterior, 4 cerdas apicais dorsais, 1 fileira ventral de cerdas; tíbia posterior, 1 cerda apical ventral. Asa (Fig. 5F): hialina, amarelada, com manchas marrons nas veias transversais dmcu e r-m; costa sem mancha marrom; ápice de $R_{2+3}$ e até o ápice de $M_{1}$ sem manchas; $C u A_{2}$ sem manchas; CuA+CuP curta; lóbulo anal com $A_{1}$ curta e fraca. Halter amarelo.

Abdome (Fig. 7F): coloração amarelada, sem borda escura (marrom) nos tergitos.

Terminália masculina (Figs. 9E, 10E): singosternito 7-8 simples, em forma de sela. Epândrio, em vista lateral, estreito anteriormente e afunilado posteriormente, com extremidade triangular, com muitas cerdas. Surstilo articulado ao epândrio, levemente esclerotizado, superfícies dorsal e dorsolateral com cerdas. Cercos simples, arredondado, com cerdas. Falo com espinhos internos dispostos longitudinalmente, em vistas lateral e dorsoventral, ápice do falo arredondado, voltado internamente; base do falo sem abaulamento. Hipândrio com parte mediana larga e lobos direcionados posteriormente. Pósgonito sem projeção digitiforme. Falapódema cerca de 0,5X a medida relativa do falo. Ápodema ejaculatório largo, localizado dorsoventralmente do lado direito.

Terminália feminina (como na Fig. 11A-D): Idem descrição do gênero.

Distribuição: Estados Unidos, México, Guatemala, Costa Rica, Colômbia e Brasil (Maranhão, Piauí e Ceará).

Material estudado: COLÔMBIA. META. PNN Sierra de La Macarena, Caño Curía. Parcela, $3^{\circ} 21^{\prime} \mathrm{N} 73^{\circ} 56^{\prime} \mathrm{W}, 460 \mathrm{~m}$, Malaise, 17.01.2003-09.02.2003, W. Villalba leg. M. 3528, 4 ㅇ (IAvH-E); idem, 321' N 7356' W, 460m, Malaise 1, 24.02.2003 10.03.2003, W. Villalba Leg. M.3530, 1 q (IAvH-E). BOLIVAR, SFF Los Colorados, Alto el Mirador, 954' N 75²' W, 400m, Malaise, 06.12.2001-21.12.2001, E. Deulufeut Leg. M.2628, 1 ๙ (IAvH-E). BRASIL. MARANHÃO. Caxias, Zona Rural, Riacho Lamego, 0448'52" S/4320'39" W, Varredura, 24.vii.2012, J.A. Rafael, F. Limeira de Oliveira \& J.S. Pinto Junior, 1 q (CZMA); idem, 0448'52" S/4320'39" W, Varredura, 24.vii.2012, J.A. Rafael, F. Limeira de Oliveira \& J.S. Pinto Junior, 1 ( (CZMA); Picadinho, Zona Rural, Riacho Lamego, 0448'52”' S/4320'38” W, Varredura, 24.vii.2012, J.A. Rafael, F. Limeira de Oliveira \& J.S. Pinto Junior, 1 \& (CZMA); Bom Jardim, REBIO - Res. Biol. Gurupi, Armadilha Suspensa, 02-11.ix.2010, F. Limeira de Oliveira, E. A. S. Barbosa \& J.C. Silva, 1 (CZMA); Res. Biol. Gurupi, MacPhail hidrolisada, 01-06.xi.2010, F. Limeira de Oliveira, C. A. E. S. Barbosa, cols., 2 , 6 § (CZMA); Mirador, Parte Est. Mirador, Posto Avançado do Mel, 0643'50" S/4458'59" W, Armadilha Malaise, 11-17.x.2015, F. Limeira de Oliveira, L.L. Santos \& T.L. Rocha, cols., $1 \hat{\delta}$ (CZMA); Base de Geraldina, $06^{\circ} 37^{\prime} 25^{\prime \prime} \mathrm{S} / 45^{\circ} 52^{\prime} 08^{\prime \prime}$ W, Armadilha suspensa, 14-18.viii.2012, F. Limeira de Oliveira, J.S. Pinto Júnior \& D.W.A. Marques, 1 đ (CZMA); idem, 06³7’25” S/4552’08” W, 
Armadilha malaise, 13-19.x.2012, F. Limeira de Oliveira, I.L.M. Santos \& L.S. Santos, 1 ๙ (CZMA). PIAUÍ. Piracuruca, P. N. de Sete Cidades, Posto do ICMBio, 0405'57' S/4142'34" W, Malaise, 17-19.vii.2012, J.A. Rafael, F. Limeira de Oliveira \& J.S. Pinto Junior, 3 (CZMA); idem, $04^{\circ} 05^{\prime} 57^{\prime \prime}$ S $/ 41^{\circ} 42$ '34" W Malaise, 17-19.vii.2012, J.A. Rafael, F. Limeira de Oliveira \&

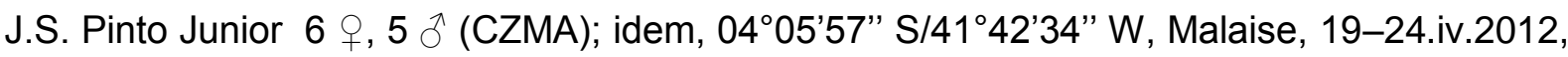
J.A. Rafael, F. Limeira de Oliveira, cols., 2 \% (CZMA); idem, $04^{\circ} 05^{\prime} 57^{\prime \prime} \mathrm{S} / 41^{\circ} 42^{\prime} 34^{\prime \prime} \mathrm{W}$, Armadilha suspensa, 16-31.i.2013, F. Limeira de Oliveira, J. S. Pinto, cols., 1 + (CZMA); idem, 04 $05^{\prime} 57^{\prime \prime}$ S $/ 41^{\circ} 42^{\prime} 34^{\prime \prime}$ W, Malaise, 12-27.iii.2013, F. Limeira de Oliveira, T.T.A. Silva, cols., 2 ㅇ (CZMA); idem, 04 $05^{\prime} 57^{\prime \prime}$ S/4142'34" W, Malaise, 16-28.ii.2013, F. Limeira de Oliveira,

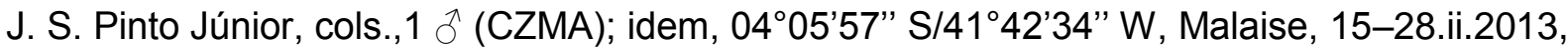
J.A. Rafael, F. Limeira de Oliveira, cols., 2 q (CZMA). CEARÁ. Ubajara, Parque Nac. de Ubajara, Cachoeira do Cafundó, 0350'13" S/4054'35" W, Armadilha Malaise 21-24.iv.2012, J.A. Rafael, F. Limeira de Oliveira, cols., 1 q (CZMA); idem, 0350'13" S/4054'35" W, Armadilha Malaise, 16-31.xii.2012, F. Limeira de Oliveira, J. S. Pinto Júnior, cols., $1 \widehat{\delta}$ (CZMA); idem, $03^{\circ} 50^{\prime} 13^{\prime \prime}$ S/4054'35' W, Armadilha Malaise, 13-17.xi.2012, F. Limeira de Oliveira, D. W. A. Marques cols., 1 क (CZMA); idem, 0350'13" S/4054'35" W, Armadilha Malaise, 01 15.xi.2012, F. Limeira de Oliveira, J. S. Pinto Júnior, cols., 1 + (CZMA); idem, 0350'13" S/4054'35" W, Armadilha Malaise, 01-14.ii.2013, F. Limeira de Oliveira, J. S. Pinto Júnior, cols., 1 \& (CZMA).

\section{Allominettia xanthiceps (Williston, 1897)}

(Figs. 1E, 2E, 3E, 4E, 5E, 6E, 7E, 8A-B, 9D, 10D, 11A-B, $12 \mathrm{M}-\mathrm{O}$ )

Allominettia xanthiceps (Williston, 1897: 9; Sapromyza). Localidade tipo: Brasil, "Piedra Blanco". Lectótipo macho, n 20 253, AMNH.

Diagnose: parafrontália com mancha oval, marrom; tíbia média com 6 cerdas anterodorsais; asa com costa amplamente marrom; veia $\mathrm{CuA}_{2}$ amplamente manchada.

\section{Re-descrição.}

Cabeça (Figs. 2E, 3E): vértice arredondado. Fronte amarela a castanha; parafrontália com mancha oval, marrom; ângulo fronto-facial $90^{\circ}$; perfil convexo. Face convexa; margem bucal ampla. Parafaciália e gena estreitas; gena com cerdas curtas, marrom. Olho arredondado, mais alto do que largo, margem posterior sinuosa. Antena: escapo e pedicelo amarelos; arista marrom, plumosa. Occipício castanho claro. Quetotaxia: distância da cerda 
fronto-orbital anterior em relação à margem ocular menor do que essa distância para a cerda fronto-orbital posterior; cerdas supravibrissais marrons, curtas e finas.

Tórax (Fig. 4 El): mesonoto castanho; pleura amarela. Quetotaxia: cerda intra-alar presente e bem desenvolvida; 1 cerda catepisternal; 2 cerdas escutelares, cerdas apicais divergentes. Pernas: amareladas. Quetotaxia: coxa média, 4 cerdas apicais; tíbia média, 4 esporões apicais ventrais, 6 cerdas anterodorsais (Fig. 6E). Asa (Fig. 5E): hialina, amarelada, com manchas marrons nas veias transversais dm-cu e r-m; costa amplamente marrom; ápice de $R_{2+3}$ escurecido, estendendo-se até o ápice de $M_{1} ; C_{u} A_{2}$ amplamente manchada; $C u A+C u P$ curta; lóbulo anal com $A_{1}$ fraca, quase tocando a margem. Halter amarelo.

Abdome (Fig. 7E): amarelado, borda dos tergitos escura (marrom).

Terminália masculina (Figs. 9D, 10 D): Sintergosternito 7-8 simples, em forma de sela. Epândrio, em vista lateral, com formato estreito anteriormente e largo posteriormente, com extremidades arredondadas, com muitas cerdas. Surstilo articulado ao epândrio, levemente esclerotizado, superfícies dorsal e dorsolateral com cerdas. Cerco simples, arredondado, com cerdas. Falo com espinhos internos dispostos longitudinalmente, em vista lateral, e em vista dorsoventral, ápice do falo arredondado, curvando-se para a parte interna; base do falo abaulada. Parte mediana do hipândrio larga, sem lobos direcionados posteriormente. Pósgonito sem projeção digitiforme. Falapódema cerca de 1,5X a medida relativa do falo. Ápodema ejaculatório largo, localizado dorsoventralmente, no lado direito.

Terminália feminina (como na Fig. 11A-D): Idem descrição do gênero.

Distribuição: Equador, Peru, Brasil (Amazonas, Pará, Maranhão, Tocantins, Rondônia, Mato Grosso do Sul e São Paulo).

Material estudado: PERU. MADRE DE DIOS. Puerto Maldonado, 8.i.1984, leg. L. Huggert, 1 ( (MZLU); Loreto, Iquitos, Barillal, 10.ii.1984, leg. L. Huggert, 19 (MZLU); idem, 10.ii.1984, leg. L. Huggert, 1 đ (MZLU). BRASIL. AMAZONAS. Rio Nhamundá, Cuipiranga,

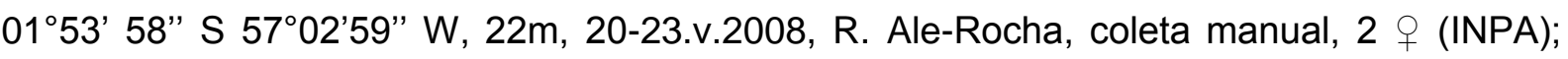
Manaus, R. Ducke, 23-ix-1986, Luis - Ulysses, 1 \& (INPA). PARÁ. R. Tocantins, próx. Cid. N. dos Patos, 11.04.1981, 1 q (INPA); Novo Repartimento, RI Pakaranã, 100m, 04²9' 05" S 49 50' 21" W, 05.iv.2008, arm. luz, J. A. Rafael, F. F. Xavier $F^{\circ}$ cols., 1 q (INPA). MARANHÃO. Caxias, R. E. Inhamum, Coités, 04 54' 43" S $143^{\circ} 25^{\prime} 30^{\prime \prime} \mathrm{W}$, Varredura, 15.vii.2016, F. Limeira de Oliveira, V.C. Silva, L.L.M. Santos, D. Limeira cols., 19 (CZMA); idem, Faz. Bode, $2^{\circ}$ Distrito, $04^{\circ} 36^{\prime} \mathrm{S} / 43^{\circ} 08^{\prime} \mathrm{W}$, Arm. Malaise, F. L. Oliveira, M. M. Ramos $\&$ R. Meneses cols, 1 क (INPA); Carolina, PARNA Chapada das Mesas, Riacho Sucuruiu, 240m, $07^{\circ} 07^{\prime}$ 05.6" S $147^{\circ} 18^{\prime} 31.6^{\prime \prime}$ W, Malaise 01, 10.i.2014, J. A. Rafael, F. Limeira-de- 
Oliveira, T.L. Rocha \& S. Pereira cols., 2 (CZMA); idem, 07 07' 05.6” S /47 18' 31.6" W, Malaise, 14-30.vi.2013, J. A. Rafael, F. Limeira-de-Oliveira, T. T. A. Silva cols., 1 đิ (CZMA). TOCANTINS. Conceição do Rio, Rio do Peixe, 420m, $11^{\circ} 22^{\prime}$ 05" S 46 55' 12"' W, 28.iii.2008, arm. luz, J. A. Rafael, F. F. Xavier $F^{\circ}$ cols, 1 (INPA). RONDÔNIA. Porto Velho, Rio Madeira, S $9^{\circ} 26^{\prime}$ 14,6" W 64 49' 58.2', Malaise 3ª camp, T1 e T3, 20.vi-01.vii.2010, Silva \& Feitosa col., 3ㅇ, $1 \hat{\delta}$ (MZUSP); Área Mutum, AHE Jirau, Transectos M5-M7 (Margem esquerda), 11 Campanha, S $9^{\circ} 35^{\prime}$ 29,5” W 65 02' 57.6”, Malaise, 17.vi-01.vii.2012, Sanhudo, C.E.D. \& Andriolli, F. col., 1 + (MZUSP). MATO GROSSO DO SUL. Aquidauana, Reserva Ecológica UEMS, S $20^{\circ} 26$ ' 03,7' W 055 39' 22,6", Malaise 07, 27.viii-11.ix.2011, Lamas, Ninhei \& eq. col., 1 + (MZUSP); Aquidauana, Res. Ecol. UEMS, Veg. Fechada, Floresta Estacional Decidual, S $20^{\circ} 26^{\prime}$ 03,7' W 55³9' 20.8', Malaise 07, 11-26.ix.2011, Lamas, Nihei \& eq. col., 1 q (MZUSP). SÃO PAULO. Ribeirão Preto, Campus USP, Reflorestamento, Mancha secundária recente, $21^{\circ} 10^{\prime}$ 05.53" S 47 51' 23.55' W, 16-31.i.2015, Amorim D.S. \& eq. cols.,

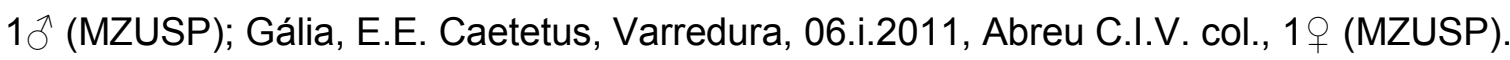

\section{Allominettia sp. nov. 1}

(Figs. $1 \mathrm{H}, 2 \mathrm{H}, 3 \mathrm{H}, 4 \mathrm{H}, 5 \mathrm{H}, 6 \mathrm{H}, 7 \mathrm{H}, 9 \mathrm{G}, 10 \mathrm{G}$ )

Diagnose: parafrontália sem mancha; tíbia média com 4 cerdas anterodorsais; asa com costa amplamente marrom; veia $\mathrm{CuA}_{2}$ levemente manchada.

\section{Descrição.}

Cabeça (Figs. 2H, 3H): Quetotaxia: distância da cerda fronto-orbital anterior até a margem ocelar menor em relação à essa distância para a cerda fronto-orbital posterior.

Tórax (Fig. 4H): mesonoto amarelo; pleura amarela. Quetotaxia: apenas uma intraalar desenvolvida; 2 cerdas catepisternais; 2 cerdas escutelares, apicais divergentes. Pernas: amareladas. Quetotaxia: coxa média, 4 cerdas apicais; tíbia média, 4 esporões apicais ventrais, 4 cerdas anterodorsais (Fig. 6H). Asa (Fig. 5I): hialina, amarelada, com manchas marrons nas veias transversais dm-cu e r-m; costa amplamente marrom; ápice de $R_{2+3}$ escurecido, estendendo-se até o ápice de $\mathrm{M}_{1} ; \mathrm{CuA}_{2}$ fortemente manchada; $\mathrm{CuA}+\mathrm{CuP}$ curta; lóbulo anal com $A_{1} 2 x$ mais longa que $\mathrm{CuA}+\mathrm{CuP}$, fraca. Halter amarelo.

Abdome (Fig. 7H): coloração amarelada sem borda escura (marrom) nos tergitos.

Terminália masculina (Figs. 9G, 10G): singosternito 7-8 simples, em forma de sela. Epândrio, em vista lateral, estreito anteriormente e largo posteriormente, com extremidade arredondada em vista lateral, com muitas cerdas. Surstilo não articulado ao epândrio, 
levemente esclerotizado, superfícies dorsal e dorsoventral com cerdas. Cercos simples, arredondado, com cerdas. Falo com espinhos internos dispostos longitudinalmente, em vista lateral e dorsoventral; ápice do falo arredondado em vista lateral, voltado internamente; base do falo sem abaulamento. Hipândrio com parte mediana muito estreita e presença de lobos direcionados posteriormente. Pósgonito com projeção digitiforme. Falapódema cerca de 0,5X a medida relativa do falo. Apódema ejaculatório largo, localizado dorsoventralmente no lado esquerdo.

Terminália feminina (como na Fig. 11A-D): Idem descrição do gênero.

Distribuição: Colômbia (Putumayo).

Material tipo: Holótipo macho. COLÔMBIA. PUTUMAYO. PNN La Paya, Resguardo Cecilio Cocha, $0^{\circ} 11^{\prime} \mathrm{S} 74^{\circ}$ 55’ W, 190m, Malaise, 20.01.2003-24.01.2003, C. Sarmiento leg., M. 3419 (IAvH-E).

\section{Allominettia sp. nov. 2,}

(Figs. 1I, 2I, 3I, 4I, 5I, 6I, 7I, 9H, 10H)

Diagnose: parafrontália sem mancha; tíbia média com 4 cerdas anterodorsais; asa com costa amplamente marrom; veia $\mathrm{CuA}_{2}$ sem manchas.

\section{Descrição.}

Cabeça (Figs. 2l, 3l): Quetotaxia: distância da cerda fronto-orbital anterior à margem ocelar igual à essa distância para acerda fronto-orbital posterior.

Tórax (Fig. 4l): mesonoto amarelo; pleura amarela. Quetotaxia: 2 cerdas intra-alares; 2 cerdas catepisternais; 2 cerdas escutelares, apicais divergentes. Pernas: amareladas. Quetotaxia: coxa média, 4 cerdas apicais; tíbia média, 4 esporões apicais ventrais, 4 cerdas anterodorsais (Fig. 6H). Asa (Fig. 5I): hialina, amarelada, com manchas marrons nas veias transversais dm-cu e r-m; costa sem manchas; ápice de $R_{2+3}$ até o ápice de $M_{1}$ sem manchas; $\mathrm{CuA}_{2}$ sem manchas; CuA+CuP curta; lóbulo anal com $A_{1} 2 x$ mais longa que CuA+CuP, fraca. Halter amarelo.

Abdome (Fig. 7l): coloração amarelada, sem borda escura (marrom) nos tergitos.

Terminália masculina (Figs. 9G, 10G): singosternito 7-8 simples, em forma de sela. Epândrio, em vista lateral, estreito anteriormente e afunilado posteriormente, com extremidade triangular, com muitas cerdas. Surstilo não articulado ao epândrio, levemente esclerotizado, 
superfícies dorsal e dorsoventral com cerdas. Cercos simples, arredondado, com cerdas. Falo com espinhos internos dispostos longitudinalmente, em vistas lateral e dorsoventral; ápice do falo, em vista lateral, bifurcado e voltado internamente; base do falo sem abaulamento. Hipândrio, em vista dorsoventral, com formato de fita e largura uniforme e presença de lobos direcionados posteriormente. Pósgonito sem projeção digitiforme. Falapódema cerca de 0,5X a medida relativa do falo. Apódema ejaculatório largo, localizado dorsoventralmente na região central.

Terminália feminina (como na Fig. 11A-D): Idem descrição do gênero.

Distribuição: Colômbia (Magdalena).

Material tipo: Holótipo macho. COLÔMBIA. MAGDALENA. PNN Tayrona, Camino Cañaveral, Arrecifes, $11^{\circ} 18^{\prime}$ N 735' W, 50m, Red, 21.07.2002-23.07.2002, M. Sharkey, D. Arias \& E. Torres Leg. M.4172. Parátipos: mesmos dados do holótipo, 1 đ (IAvH-E); idem, $11^{\circ} 20^{\prime} \mathrm{N} 74^{\circ} 2^{\prime} \mathrm{W}, 70 \mathrm{~m}$, Red, 18-20.vii.2002, M. Sharkey, D. Arias \& E. Torres Leg. M.4171, 3

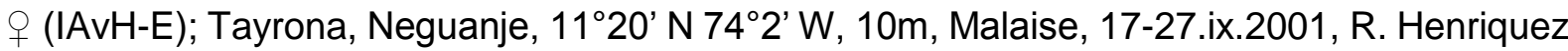
Leg., M.2136, 2 q (IAvH-E); Borde camino Pueblito-Cañaveral, 1120'N 742'W, 30, Red, M. Sharkey, D. Arias \& E. Torres, M. 3268, 1 \& (IAvH-E).

\section{Allominettia sp. nov. 3}

(Figs. 1K, 2K, 3K, 4K, 5K, 6K, 7K, 9J, 10J)

Diagnose: parafrontália sem mancha; tíbia média com 6 cerdas anterodorsais; asa com costa amplamente marrom; veia $\mathrm{CuA}_{2}$ sem manchas.

\section{Descrição.}

Cabeça (Figs. 2K, 3K): Quetotaxia: distância da cerda fronto-orbital anterior à margem ocelar igual à essa distância para a cerda fronto-orbital posterior.

Tórax (Fig. 4K): mesonoto amarelo; pleura amarela. Quetotaxia: 2 cerdas intra-alares; 2 cerdas catepisternais; 2 cerdas escutelares, apicais divergentes. Pernas: amareladas. Quetotaxia: coxa média, 4 cerdas apicais; tíbia média, 4 esporões apicais ventrais, 6 cerdas anterodorsais (Fig. 5K). Asa (Fig. 5K): amarelada, com manchas ou marcas marrons nas veias transversais dm-cu e r-m; costa sem manchas; ápice de $R_{2+3}$ até o ápice de $M_{1}$ sem manchas; $\mathrm{CuA}_{2}$ sem manchas; CuA+CuP curta; lóbulo anal com $A_{1} 2 x$ mais longa que $C u A+C u P$, fraca. Halter amarelo.

Abdome: coloração castanha, sem borda escura (marrom) nos tergitos. 
Terminália masculina (Figs. 9J, 10J): singosternito 7-8 simples, em forma de sela. Epândrio, em vista lateral, retangular; com extremidade arredondada, em vista lateral, com muitas cerdas. Surstilo não articulado ao epândrio, levemente esclerotizado, superfícies dorsal e dorsoventral com cerdas. Cercos simples, arredondado, com cerdas. Falo com espinhos internos longitudinalmente, em vistas lateral e dorsoventral; ápice do falo arredondado, em vista lateral, voltado internamente; base do falo sem abaulamento. Hipândrio, em vista dorsoventral, com parte mediana larga e presença de lobos direcionados posteriormente. Pósgonito sem projeção digitiforme. Falapódema cerca de $0,5 \mathrm{X}$ a medida relativa do falo. Apódema ejaculatório largo, localizado dorsoventralmente no lado direito.

Terminália feminina (como na Fig. 11A-D): Idem descrição do gênero.

Distribuição: Colômbia.

Material tipo: Holótipo macho. COLÔMBIA. META. PNN Sierra de La Macarena, Caño Curía, Parcela, 321'N 7356'W, 460m, Malaise, 24.02.2003-10.03.2003, W. Villalba, 3525, 1 ô (IAvH-E). Parátipo: COLÔMBIA. META. PNN Sierra de La Macarena, Caño Curía, Parcela, 321' $\mathrm{N} 73^{\circ} 56$ 'W, 460m, Malaise, 24.02.2003-10.03.2003, W. Villalba, 3525, 1 우 (IAvH-E).

\section{Chave de identificação para as espécies de Allominettia Hendel}

1) Parafrontália com mancha oval, marrom (Fig. 2E)

A. xanthiceps

- Parafrontália sem mancha oval, marrom (Fig. 2F)

2) Asa com veia $\mathrm{CuA}_{2}$ levemente manchada (Fig. $5 \mathrm{H}$ )

A. sp. nov. 1

- Asa com veia $\mathrm{CuA}_{2}$ sem manchas (Fig.5K)

3) Abdome com coloração castanha (Fig. 7J) 4

- Abdome com coloração amarela (Fig. 7K) A. sp. nov. 3

4) Tíbia média com três ou quatro cerdas anterodorsais (Fig. 6l-J) 5

- Tíbia média com cinco cerdas anterodorsais (Fig. 6F) A. geniseta

5) Mancha no tergito 3 ausente (Fig. 7I) 6 Mancha no tergito 3 presente (Fig. 7G) A. approximata

6) Tíbia média com três cerdas anterodorsais (Fig. 6H) A. sp. nov. 2 
- Tíbia média com quatro cerdas anterodorsais (Fig. 6J)

A. assimilis

\section{Lista de caracteres}

Os 49 caracteres utilizados na análise cladística são apresentados a seguir.

\section{Cabeca}

1. Cor do vértice da cápsula cefálica: 0 = amarelado, contrastando com o triângulo ocelar; $1=$ castanho, da mesma cor que o triângulo ocelar.

2. Cor do triângulo ocelar: 0 = amarelo; 1 = castanho

3. Mancha na parafrontália: $0=$ ausente; $1=$ presente

4. Largura da gena comparada à altura do olho: $0=$ em torno de um quinto da altura do olho; 1 = maior que metade da altura do olho

5. Tamanho das cerdas da gena: $0=$ curtas; $1=$ longas

6. Relação comprimento/largura do primeiro flagelômero: 0 = claramente maior que $1.5 x ; 1=$ menor ou igual a $1.5 \mathrm{x}$

7. Comprimento da cerda vertical interna comparado ao comprimento da cerda vertical externa: 0 = maior que 2 vezes; 1 = menor que 2 vezes

8. Distância da cerda fronto-orbital anterior à margem ocelar em relação à essa distância para a cerda fronto-orbital posterior: 0 = mesma distância; 1 = menor distância

\section{Tórax}

9. Faixa mediana no mesonoto: $0=$ presente; $1=$ ausente

10. Sétulas no escutelo: $0=$ presentes; 1 = ausentes

11. Cerda intra-alar: $0=$ ausente; $1=$ presente

12. Número de fileiras de sétulas acrosticais entre as dorsocentrais: $0=$ nenhuma; $1=$ duas ou mais

13. Número de cerdas catepisternais: $0=$ nenhuma; $1=$ uma; $2=$ duas 


\section{$\underline{\text { Perna }}$}

14. Número de cerdas apicais na coxa anterior: $0=$ uma; 1 = três; $2=$ quatro; $3=$ duas

15. Fileira de cerdas ventrais no fêmur anterior: $0=$ ausente; $1=$ presente

16. Tíbia anterior $/$ cerdas apicais dorsais: $0=0$ cerda; $1=1$ cerda; $2=$ cerdas

17. Tíbia anterior/cerda apical ventral: $0=$ ausente; $1=$ presente

18. Cor do basitarso nas pernas anterior, média e posterior: $0=$ branco, contrastando com os demais tarsômeros; 1 = castanho, da mesma cor que os demais tarsômeros; 2 = amarelado

19. Número de cerdas apicais na coxa média: $0=3$ cerdas; $1=4$ cerdas; $2=5$ cerdas

20. Fileira de cerdas ventrais no fêmur médio: 0 = ausente; $1=$ presente

21. Cor da tíbia média: 0 = branca; 1 = marrom avermelhado; 2 = amarela

22. Cerdas ântero-dorsais na tíbia média: 0 = inúmeras cerdas de tamanhos iguais; $1=$ pelo menos 4 bem fortes

23. Tíbia média/número de esporões apicais ventrais: $0=2 ; 1=3 ; 2=4 ; 3=1$

24. Cerdas apicais na coxa posterior: $0=1$ cerda; $1=2$ cerdas

25. Fileira de cerdas posteriores no fêmur posterior: $0=$ ausente; $1=$ presente

26. Cerda apical dorsal na tíbia posterior: $0=$ ausente; $1=$ presente

$\underline{\text { Asa }}$

27. Membrana: 0 = translucida; 1 = com uma mancha escurecida estreita em $r-m$ e dm-cu; 2 = uma mancha $\mathrm{R} 2+3 / \mathrm{R} 4+5 / \mathrm{M} 1 ; 3$ = terço distal $\mathrm{R} 2+3$ e $\mathrm{M} 1$

28. Formato da veia dm-cu: $0=$ levemente reta a côncava; $1=$ convexa

29. R1: 0 = terminando próximo à Sc; 1 = distante da Sc

30. Ápice de $\mathrm{M} 1: 0$ = reta; 1 = fortemente curva, quase fundindo-se ao ápice de R4+5

31. Cerdas na porção dorsal de R4+5: 0 = ausente; 1 = presente

32. Parte distal de $\mathrm{R} 4+5: 0$ = reta, paralela à $\mathrm{R} 2+3 ; 1=$ levemente curva, convergente com M1

33. Comprimento da veia $\mathrm{CuA}+\mathrm{CuP}: 0=$ longa; 1 = curta 
34. A1: $0=$ ausente; $1=$ presente

\section{$\underline{\text { Abdome }}$}

35. Mancha no tergito 3: 0 = ausente; 1 = presente

$\underline{\text { Terminália feminina }}$

36. Número de espermatecas: $0=2+1 ; 1=2+2$

37. Espermatecas, superfície: 0 = lisa; 1 = rugosa

38. Textura do duto único da espermateca: 0 = liso; 1 = com ondulações

\section{$\underline{\text { Terminália masculina }}$}

39. Parte mais larga do epândrio (vista lateral): $0=$ extremidade ventral; $1=$ parte mediana

40. Extremidade ventral do epândrio: $0=$ arredondada; $1=$ triangular; $2=$ em gancho

41. Base do falo: $0=$ abaulada; $1=$ sem abaulamento

42. Margem anterior do falo: $0=$ reta; $1=$ com pequena projeção

43. Margem posterior do falo: $0=$ reta; $1=$ com incisão profunda

44. Falo: 0 = largo na base; 1 = estreito na base

45. Tamanho do falo em relação ao epândrio: 0 = aproximadamente do mesmo tamanho; $1=$ duas vezes maior

46. Formato do hipândrio: 0 = fita de largura uniforme; $1=$ extremidades laterais projetadas anteriormente; 2 = extremidades laterais muito projetadas

47. Cerdas no hipândrio: 0 = ausentes; 1 = presentes

48. Lobos posteriores do hipândrio: 0 = ausentes no ponto onde o hipândrio toca o falo; $1=$ projetados

49. Formato do pós-gonito: 0 = afilado; 1 = metade basal larga, metade apical bilobada

Análise cladística 
Realizando-se a análise da matriz de caracteres (Tab. 1) com pesagem igual, construída a partir dos caracteres listados acima, foram obtidas cinco árvores (Figs. 13A-B; 14A-B; 15A) mais parcimoniosas, com 97 passos, índice de consistência (I.C.) de 61 e índice de retenção (I.R.) de 62. O consenso estrito dessas cinco árvores (Fig. 15A) - com 104 passos, I.C. de 57, e I.R. de 55 - foi utilizado como árvore referência para a Discussão, apresentada a seguir. 


\section{DISCUSSÃO}

O estudo comparado da morfologia aqui executado permitiu obter informação de especial importância para a redescrição das espécies conhecidas, a descrição de novas espécies de Allominettia, a confecção de uma chave de identificação para o gênero, que irá auxiliar novos estudos sobre a diversidade da família na região Neotropical, e a análise das relações filogenéticas realizada. O estudo da terminália masculina e feminina ampliou o conhecimento dessas estruturas e permitiu formular hipóteses de homologia resolvendo algumas questões até agora não trabalhadas no estudo do grupo.

A árvore de consenso obtida (Fig. 15B) mostra ainda falta de resolução para alguns clados e algumas hipóteses relativamente bem suportadas de monofilia. As relações entre os grupos externos receberam pouca atenção em termos de amostragem de caracteres e de amostragem taxonômica. $\mathrm{O}$ uso desses grupos externos pretendeu basicamente enraizar a árvore e estabelecer as direções das séries de transformação dos caracteres dentro do grupo interno. Assim, as relações entre os grupos externos não são o foco da análise e não têm robustez para a construção de hipóteses para a classificação do grupo.

A parte menos resolvida na análise de consenso é a politomia que contém todas as espécies de Allominettia exceto $A$. xanthiceps, e as espécies estudadas de Chaetominettia e de Deutominettia. Há três clados importantes e muito estáveis em todas as topologias obtidas-de maneira que aparecem na árvore de consenso. Um deles é um grupo monofilético incluindo todas as espécies de Allominettia, Chaetominettia e de Deutominettia. Ou seja, é bastante claro que Allominettia é parafilético em relação a esses outros dois gêneros. As sinapomorfias de "Allominettia s.l." e as sinapomorfias do grande clado exceto $A$. xanthiceps são compartilhadas por esses dois gêneros, conferindo robustez a essa hipótese. Em algumas das árvores igualmente mais parcimoniosas o pequeno clado incluindo esses dois gêneros ocupam uma posição bastante terminal dentro da filogenia, com ainda mais caracteres compartilhado entre as espécies desses dois gêneros e espécies particulares de Allominettia.

Isso vai demandar que o nome do táxon genérico mude para Deutominettia. A espécie tipo desse gênero foi utilizada na análise e o nome Deutominettia tem prioridade sobre Allominetia. Embora os nomes de ambos os gêneros tenham sido descritos pelo mesmo autor no mesmo trabalho, a página na qual aparece o nome Deutominettia é anterior àquela onde está a descrição de Allominettia.

Malloch (1926) discutiu os caracteres usados para agrupar espécies em Minettia, indicando que estudos posteriores sobre essas espécies certamente levariam a uma 
subdivisão do gênero. Por causa dessa visão sobre as características definidoras de Minettia, esse autor descreveu nesse gênero várias espécies consideradas por ele como "aberrantes", até que o estudo de material adicional da América do Sul ajudasse a elucidar a natureza distintiva (ou não) dos caracteres utilizados até então para esse grupo de gêneros. Os resultados obtidos aqui reforçam essa posição. Certamente seria interessante se mais espécies de Chaetominettia e de Deutominettia fossem analisadas para conclusões sobre a filogenia ainda mais robustas.

Uma outra hipótese importante é relação de grupo irmão entre $A$. xanthiceps e todas as demais espécies do clado. Isso aparece em todas as árvores mais curtas e permite compreender a evolução de diversos caracteres no gênero. Finalmente, ainda que com uma análise limitada a uma espécie, o fato de que Minettia não cai dentro do clado de Allominettia corresponde a uma indicação de que a preocupação inicial de Malloch (1926) de subdividir o grande complexo em torno de Minettia estava correta. Ainda que potencialmente o conjunto das espécies atualmente em Minettia ainda possa ser parafilético em relação ao clado incluindo Allominettia, Chaetominettia e Deutominettia (para o que não há evidência na análise atual), há pelo menos um subgrupo de Minettia que certamente não se agrupa dentro desse clado. Ou seja, é provável que Minettia compunha um grupo de fato à parte do clado Allominettia-Chaetominettia-Deutominettia. O fato de Griphoneura ser o grupo irmão do clado Allominettia-Chaetominettia-Deutominettia, como foi comentado, não pode, com o atual número de clados externos e características para as relações entre grupos externos, ser considerado um evidência clara de que Minettia ocupa uma posição ainda mais distante dentro de Lauxaniinae, em relação ao clado Allominettia-Chaetominettia-Deutominettia.

\section{CONCLUSÃO}

O presente trabalho contribuiu em diversos aspectos para a taxonomia e sistemática de Allominettia, avançando assim na compreensão das relações entre as espécies.

O estudo de grande quantidade de material possibilitou a descrição de três novas espécies, elevando para sete o total de espécies no gênero. As ilustrações de terminália masculina ajudaram a aprimorar as descrições e, portanto, a separação entre as espécies.

A confecção da chave dicotômica para todas as espécies de Allominettia possibilita uma identificação mais segura de suas espécies, contribuindo para o conhecimento da diversidade de dípteros neotropicais. 
Este estudo realizou a primeira análise cladística das espécies do gênero, tendo como base uma matriz elaborada com 49 caracteres e 14 táxons terminais. A árvore de consenso obtida representa um primeiro resultado para o entendimento do grupo.

\section{REFERÊNCIAS BIBLIOGRÁFICAS}

AMORIM, D.S.; SILVA, V.C. \& BALBI, M.I.P.A.. 2002. Estado do conhecimento dos Diptera neotropicais, pp. 29-36. In: COSTA, C.; VANIN, S.A.; LOBO, J.M. \& MELIC, A. (Eds). Proyecto de Redlberoamericana de Biogeografia y Entomologia Sistemática PrIBES. M3m Monografias Tercer Milênio Sociedad Entomológica Aragonesa (SEA) \& Cyted, Zaragoza. Vol. 2.

BROWN, B. V.; BORKENT, A.; CUMMING, J. M.; WOOD, D. M.; WOODLEY, N. E. \& ZUMBADO, M. A. (Eds.). 2010. Manual of Central American Diptera. NRC Research Press, Ottawa, Ontario, Canadá. Vol. 2.

BUGGUIDE. 2003-2018. Minettia fasciata, by Carr, J. F. (Contributing Editor). Disponível em: https://bugguide.net/node/view/879390/bgimage (Acesso 20/03/2018).

CARVALHO, C.J.B.; COURI, M.S.; RAFAEL, J.A.\& SILVA, V.C. 2012. Diptera, pp. 701-743. In: CARVALHO, C.J.B.; CASARI, S.A., CONSTANTINO, R.; MELO G.A.R.\& RAFAEL, J.A. (Eds), Insetos do Brasil. Holos, Ribeirão Preto.

COLLIN J. E. 1948. A short synopsis of the British Sapromyzidae (Diptera). Transactions of the Royal Entomological Society of London, 99: 225-242.

CUMMING, J.M. \& WOOD, D.M. 2009. Adult morphology and terminology, pp. 9-50. In: BROWN, B.V.; BORKENT, A.; CUMMING, J.M.; WOOD, D.M.; WOODLEY, N.E. \& ZUMBADO, M.A. (Eds), Manual of Central American Diptera. NRC Research Press, Ottawa, Ontario, Canadá. Vol. 1.

DISCOVER LIFE. 2011-2018. Sapromyza albiceps. Photos by Malcolm Storey. Disponível em: http://www.discoverlife.org/mp/20q?search=Sapromyza+albiceps

(Acesso 20/03/2018).

GAIMARI, S.D. 2004. A new genus of Lauxaniidae (Diptera) from New Caledonia. Zootaxa, 449: 1-39.

GAIMARI, S. D. \& SILVA, V. C. 2010a. Revision of the Neotropical subfamily Eurychoromyiinae (Diptera: Lauxaniidae). Zootaxa, 2342: 1-64. 
GAIMARI, S. D. \& SILVA, V. C. 2010b. Lauxaniidae (Lauxaniid flies), pp. 971-995. In: BROWN, B.V.; BORKENT, A.; CUMMING, J.M.; WOOD, D.M.; WOODLEY, N.E.\& ZUMBADO, M.A. (Eds), Manual of Central American Diptera. NRC Research Press, Ottawa, Ontario, Canadá. Vol. 2.

GOLOBOFF, P.; FARRIS, J. \& NIXON, K. 2008. TNT a free program for phylogenetic analysis. Cladistics, 24: 774-786.

HENDEL, F. 1925. Neue Ubersicht über die bisher bekannt gewordenen Gattungen der Lauxaniidae, nebst Beschreibung neuer Gattungen und Arten. Encyclopedie entomologique, serie B Dipt., II: 103-142.

HENNIG, W. 1966. Phylogenetic Systematics. Illinois University, Urbana.

KITCHING, I. J.; P. L. FOREY; C. J. HUMPHRIES \& D. M. WILLIAMS. 1998. Cladistics: the theory and practice of parcimony analysis. 2nd ed. Oxford, Oxford University (Systematic association publications 11)

LEE, H. S. \& HAN, H.Y. 2015. Nine Species of the Family Lauxaniidae (Diptera, Lauxanioidea) new to Korea. Animal Systematics, Evolution and Diversity, 31 (4): 266-276.

LI, X.; LI, W.; DING, S.; CAMERON, S. L.; MAO, M.; SHI, L. \& YANG, D. 2017. Mitochondrial Genomes Provide Insights into the Phylogeny of Lauxanioidea (Diptera: Cyclorrhapha). Int. J. Mol. Sci., 18, 773: 1-23.

MCALPINE, J. F. 1989. Phylogeny and classification of the Muscomorpha, pp. 1397-1518. In: WOOD, D.M.; MCALPINE, J.F. (Eds). Manual of Nearctic Diptera. Ottawa, Ontario: Research Branch Agriculture Canada. Vol.3.

MALLOCH, J. R. 1926. New genera and species of acalyptrate flies in the United States National Museum. Proceedings of the United States National Museum, 68 (21): 135.

MALLOCH, J. R. 1928. Notes on American two-winged flies of the family Sapromyzidae. Proceedings of the United States National Museum, 73 (23): 1-18.

MELLO, R. J. C. L. 2007. Revisão e análise cladística das espécies de Physoclypeus Hendel, 1907 (Diptera, Lauxaniidae). Dissertação (Biologia Animal) - Universidade Estadual Paulista Júlio de Mesquita Filho.

MELLO, R. J. C. L. \& SILVA, V. C. 2008. Filogenia e distribuição das espécies de Physoclypeus (Diptera, Lauxaniidae). In: Resumos do XVII Congresso Brasileiro de Zoologia XVII Congresso Brasileiro de Zoologia, Curitiba 1: 233-233 Curitiba: UFPR.

MERZ, B. 2004. Revision of the Minettia fasciata species-group (Diptera, Lauxaniidae). Revue Suisse de Zoologie, 111 (1): 183-211.

MERZ, B. 2007. Two new Mediterranean species of the Sapromyza intonsa group (Diptera, Lauxaniidae). Tijdschrift voor Entomologie, 150: 65-76. 
NIXON, C.K. 1999-2002. Winclada, Version 1.0000. Published by the author, Ithaca, New York, NY.

NIXON, C. K. \& CARPENTER, J. M. 1993. On outgroups. Cladistics, 9: 413-426.

PAPP, L. \& SHATALKIN, A.I. 1998. Family Lauxaniidae, pp. 383-400. In: PAPP, L. \& DARVAS, B. (Eds.), Manual of Palaearctic Diptera. Science Herald, Budapest Volume 3.

PAPP, L. \& SILVA, V.C. 1995. Seven new genera of the Neotropical Lauxaniidae (Diptera). Acta Zoologica Academiae Scientiarum Hungaricae, 41 (3): 185-208.

PESTANO, J., BROWN, R. P., SUÁREZ, N. M. \& BÁEZ, M. 2003. Diversification of sympatric Sapromyza (Diptera: Lauxaniidae) from Madeira: six morphological species but only four mtDNa lineages. Molecular Phylogenetics and Evolution, 27: 422-428.

REMM E, \& ELBERG, K., 1979. Terminalia of the Lauxaniidae (Diptera) found in Estonia, Latvia and Lithuania. Dipterological Research: 66-117.

SCHUH, R.T. 2000. Biological systematics: principles and applications. Cornell University, New York. USA.

SEMELBAUER, M., 2016. Molecular phylogeny of lauxaniid flies (Diptera, Cyclorrhapha) confirms non-monophyly of Sapromyza Fallén 1810. Insect Systematics \& Evolution, 47(4): 389-409.

SHEWELL, G. C. 1987. Lauxaniidae, pp 951-964. In: MCALPINE, J.F., PETERSON, B.V., SHEWELL, G.E., TESKEY, H.J., VOCKEROTH, J.R. \& WOOD, D.M. (Eds.). Manual of Nearctic Diptera, Research Branch, Agriculture Canada, Ottawa, Monograph 28. Volume 2.

SHI, L.; GAIMARI, S. D. \& YANG, D. 2012. Notes on the Homoneura subgenera Euhomoneura, Homoneura and Minettioides from China (Diptera: Lauxaniidae). Zootaxa, 3238: 1-22.

SILVA, V. C. \& GAIMARI, S. D. (em prep.) A conspectus of Neotropical Lauxaniidae (Diptera: Lauxanioidea), including a taxonomic catalogue and key to genera.

STUCKENBERG, B. R. 1971. Old World Genera of Lauxaniidae. Annals of the Natal Museum, 20: 499-610.

THOMPSON, F. C. 2008. The Diptera site. The biosystematic database of world Diptera. Nomenclator status statistics. Version 10.5. Disponível em: http://www.sel.barc.usda.gov/diptera/ names/Status/ bdwdstat.htm. (Acesso: jan/2009).

WILLISTON, S. W. 1897 Diptera Braziliana, part 4. Kansas University Quarterly, ser. A 6: 112. 
ANEXOS 


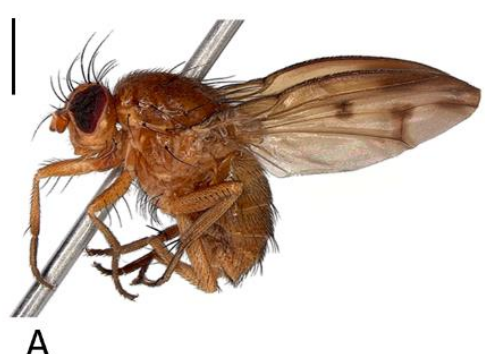

A

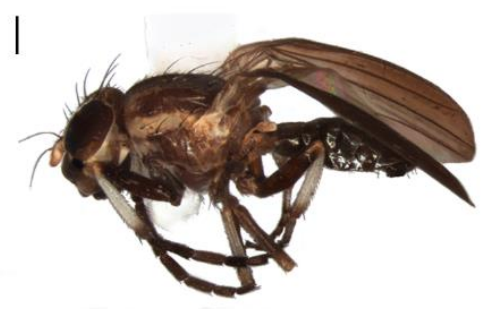

D

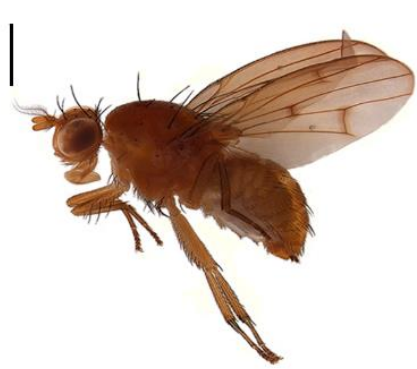

G

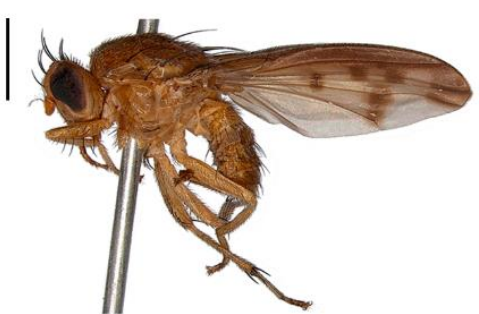

B

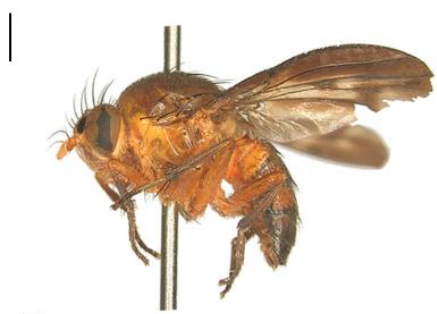

E

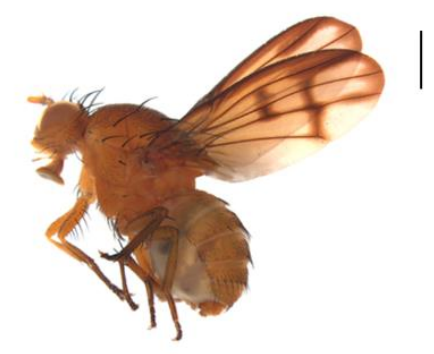

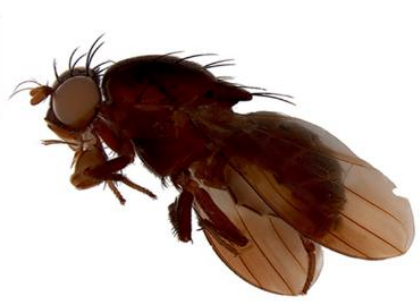

C

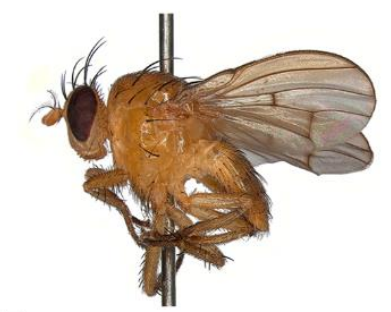

F

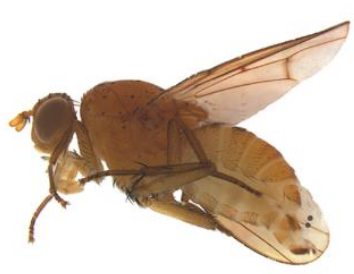

$\mathrm{H}$

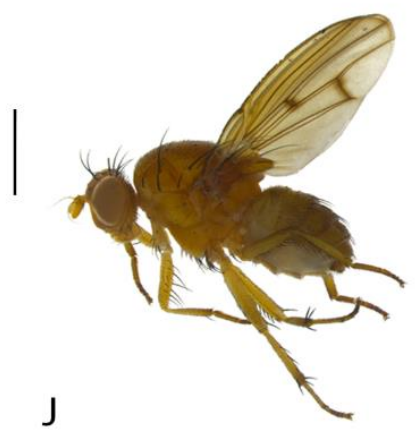

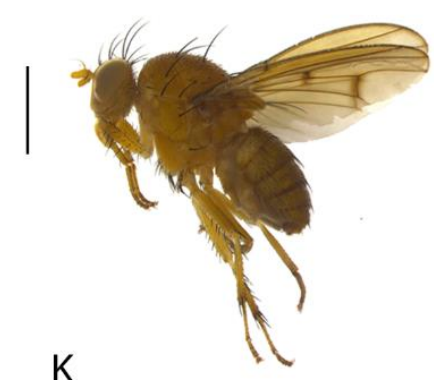

K

I

Figura 1. Habitus, vista lateral. A. Chaetominettia mactans; B. Deutominettia pulchrifrons; C. Griphoneura triangulata; D. Physegeniopsis albeto; E. Allominettia xanthiceps; F. A. geniseta; G. A. approximata; H. A. sp. nov. 1; I. A. sp. nov. 2; J. A. assimilis; K. A. sp. nov. 3. Escala 0,5 mm. 


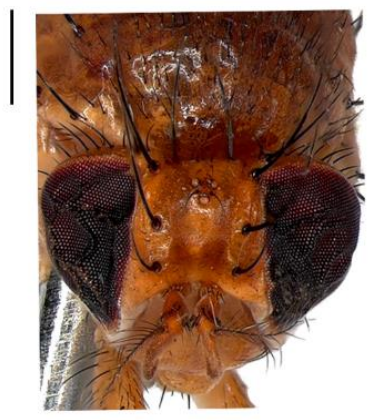

A

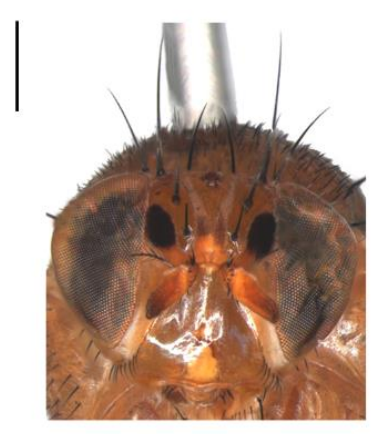

E

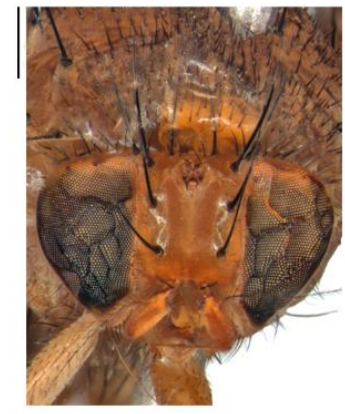

B

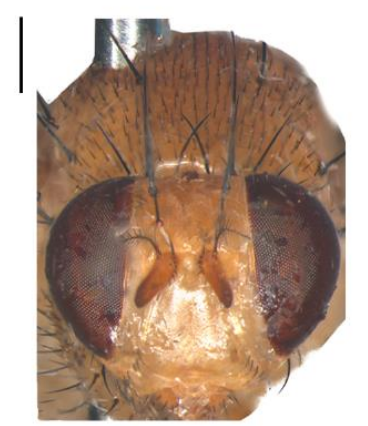

F

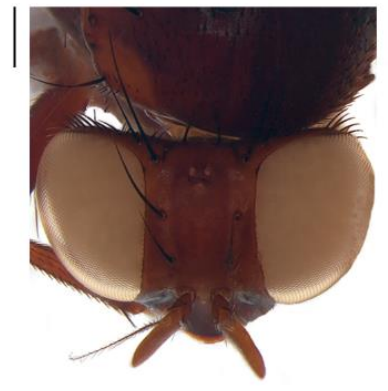

C

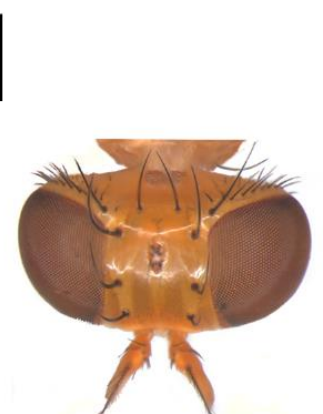

G

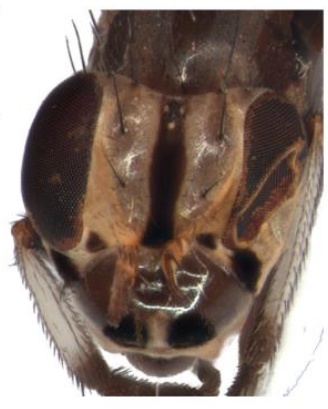

D

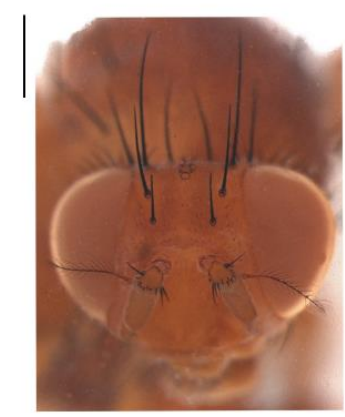

$\mathrm{H}$

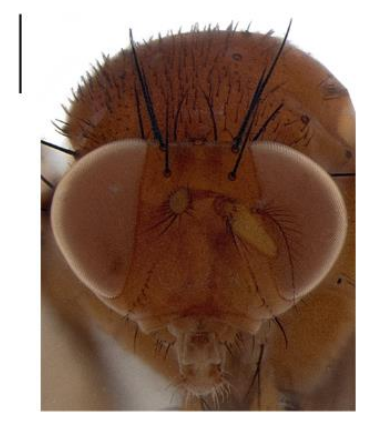

I

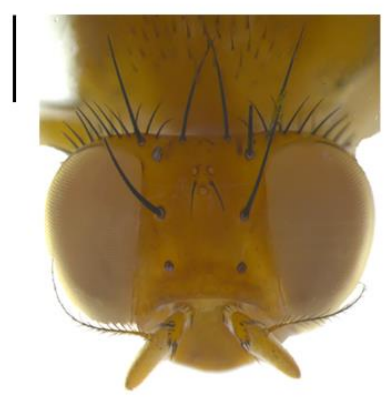

J

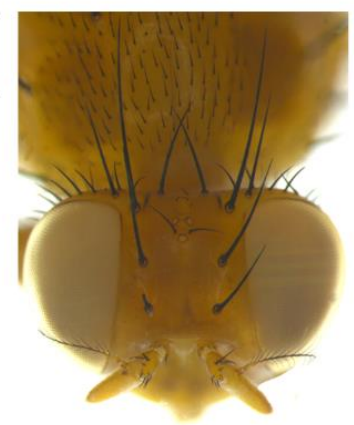

K

Figura 2. Cabeça, vistas frontal e dorsal. A. Chaetominettia mactans; B. Deutominettia pulchrifrons; C. Griphoneura triangulata; D. Physegeniopsis albeto; E. Allominettia xanthiceps; F. A. geniseta; G. A. approximata; H. A. sp. nov. 1 ; I. A. sp. nov. 2; J. A. assimilis; K. A. sp. nov. 3 . Escala 0,5 mm. 

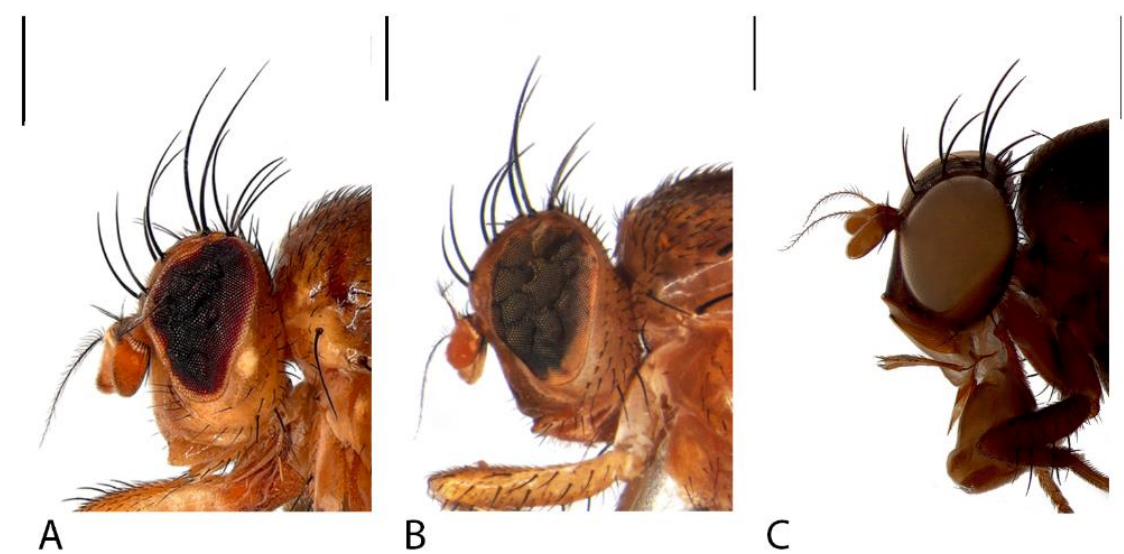

C

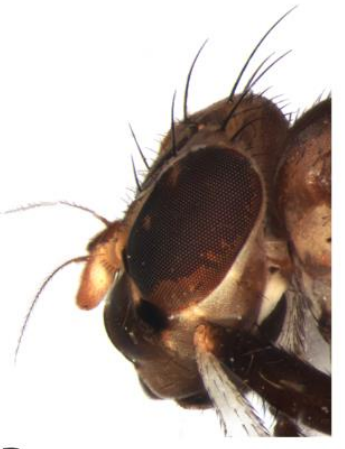

D
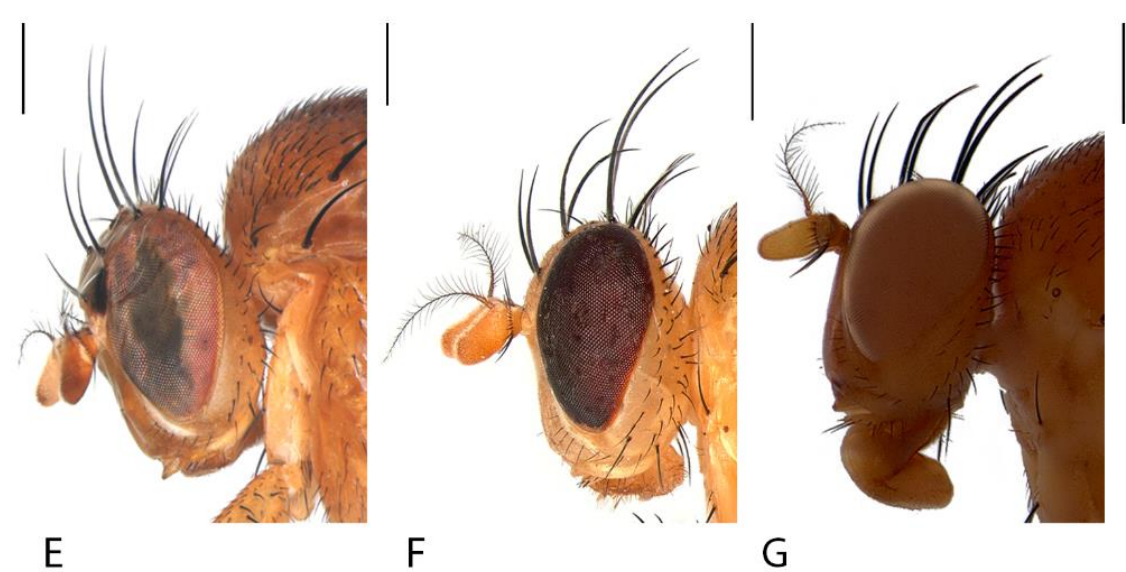

$\mathrm{F}$

G

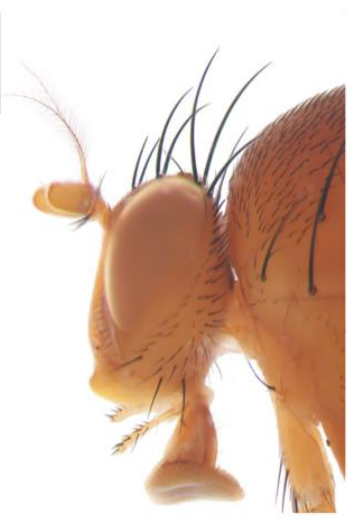

$\mathrm{H}$

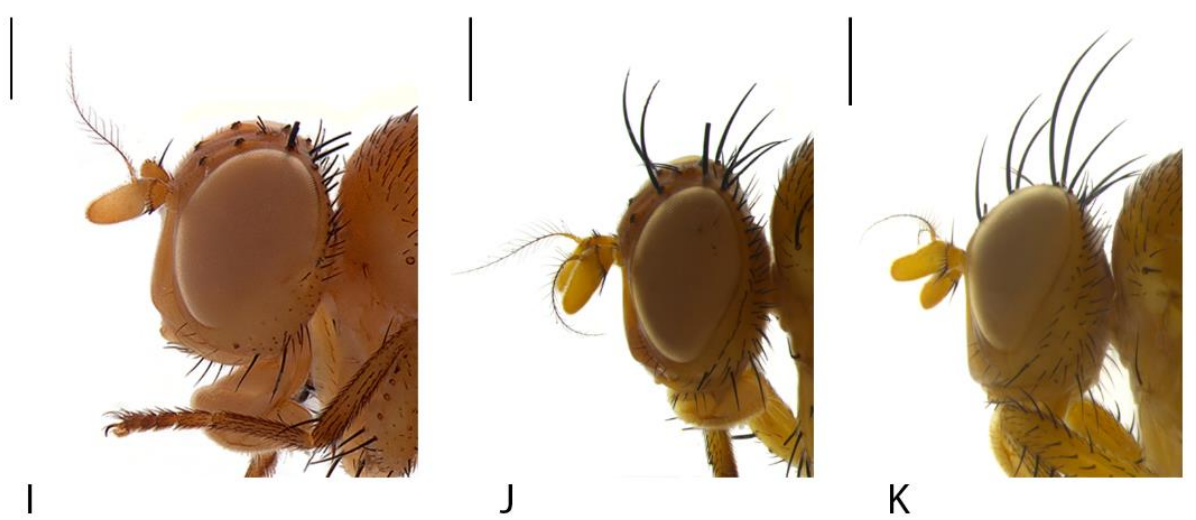

Figura 3. Cabeça, vista lateral. A. Chaetominettia mactans; B. Deutominettia pulchrifrons; C. Griphoneura triangulata; D. Physegeniopsis albeto; E. Allominettia xanthiceps; F. A. geniseta; G. A. approximata; H. A. sp. nov. 1 ; I. A. sp. nov. 2; J. A. assimilis; K. A. sp. nov. 3. Escala 0,5 mm. 


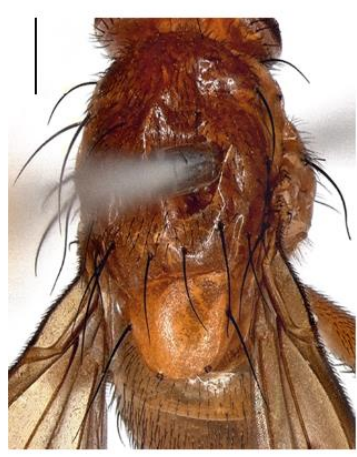

A

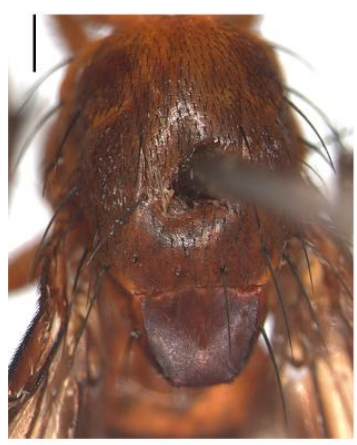

E

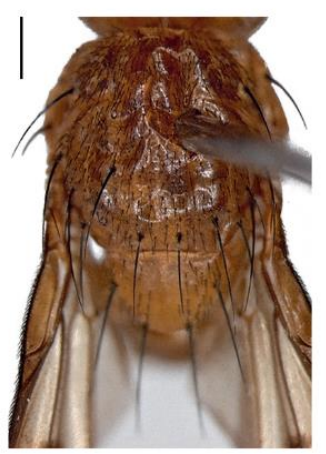

B

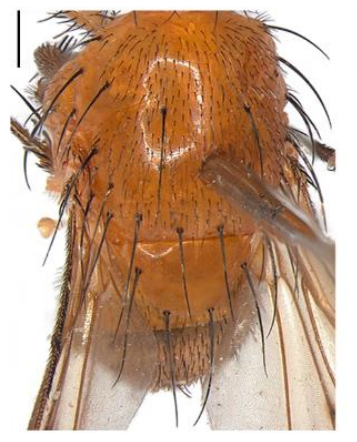

F

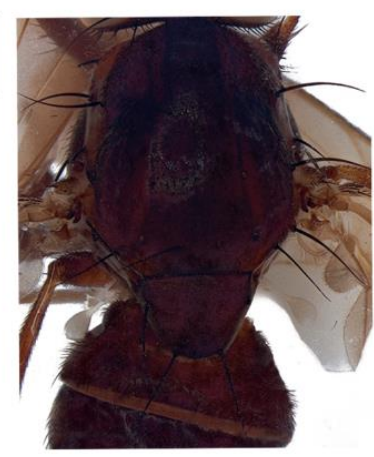

C

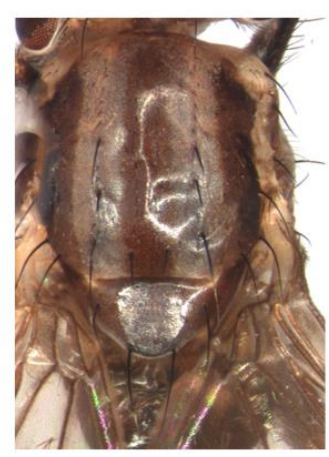

D

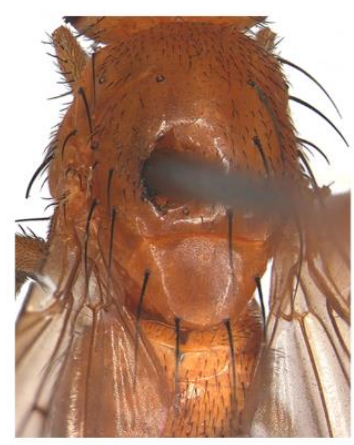

G

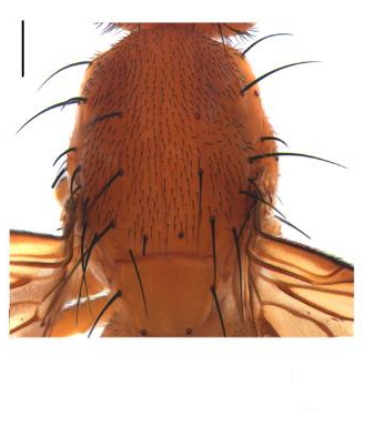

H

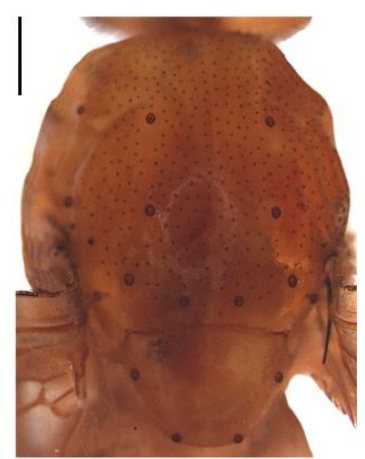

I

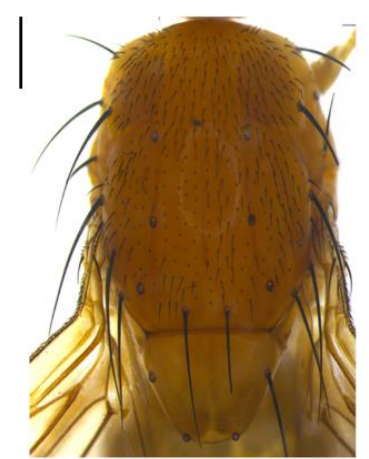

$\mathrm{J}$

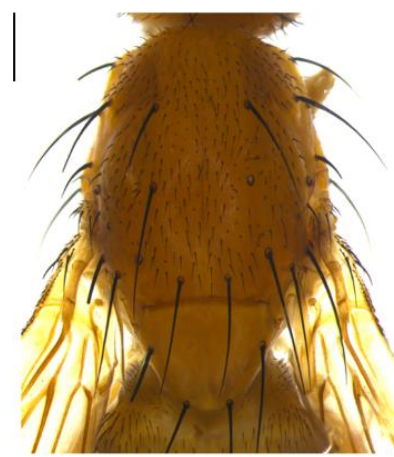

K

Figura 4. Tórax, vista dorsal. A. Chaetominettia mactans; B. Deutominettia pulchrifrons; C. Griphoneura triangulata; D. Physegeniopsis albeto; E. Allominettia xanthiceps; F. A. geniseta; G. A. approximata; H. A. sp. nov. 1 ; I. A. sp. nov. 2; J. A. assimilis; K. A. sp. nov. 3. Escala 0,5 mm. 

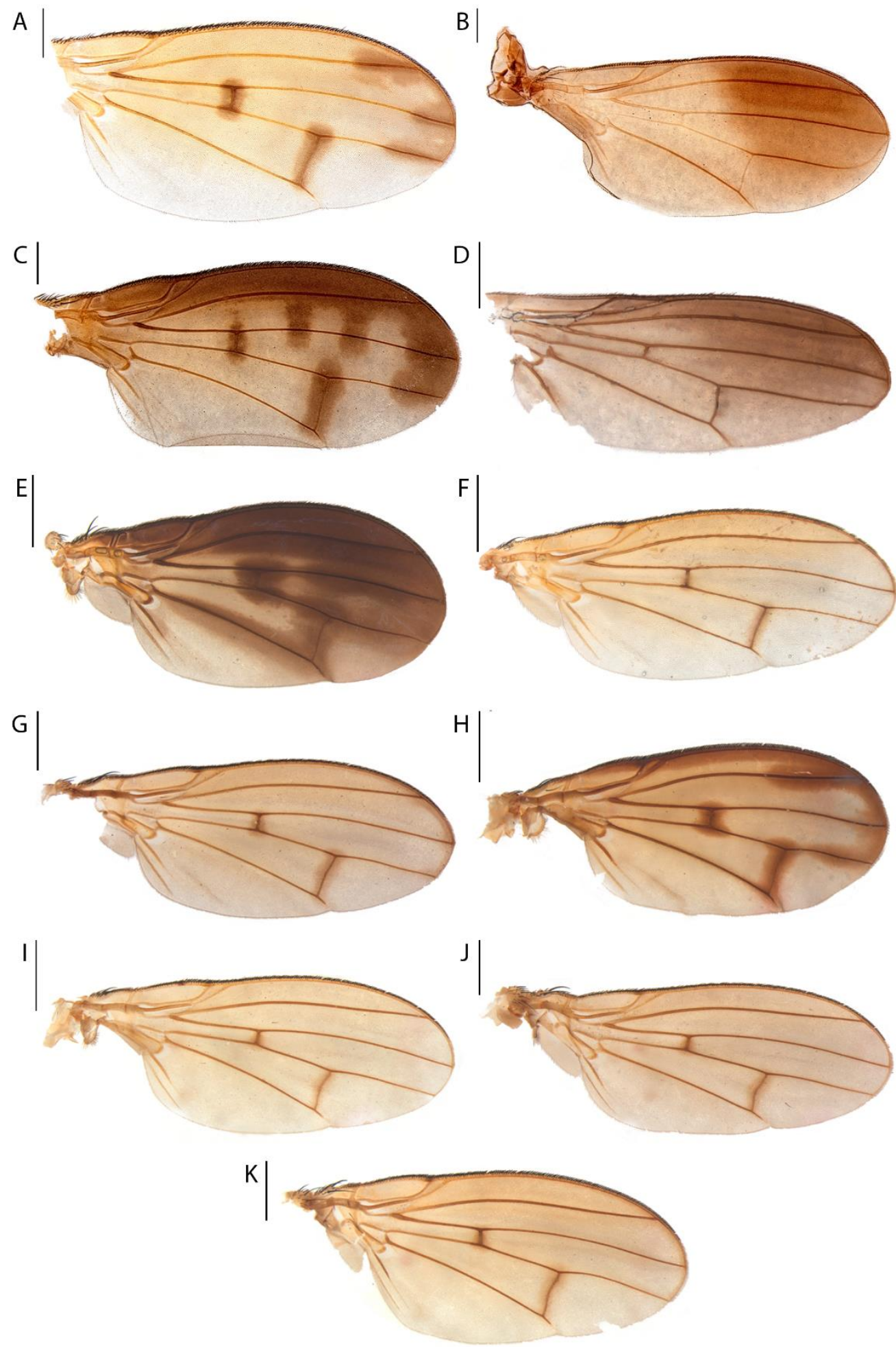

Figura 5. Asa, vista lateral. A. Chaetominettia mactans; B. Deutominettia pulchrifrons; C. Griphoneura triangulata; D. Physegeniopsis albeto; E. Allominettia xanthiceps; F. A. geniseta; G. A. approximata; H. A. sp. nov. 1; I. A. sp. nov. 2; J. A. assimilis; K. A. sp. nov. 3. Escala 0,5 mm. 


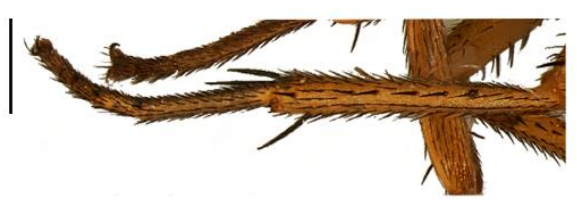

A

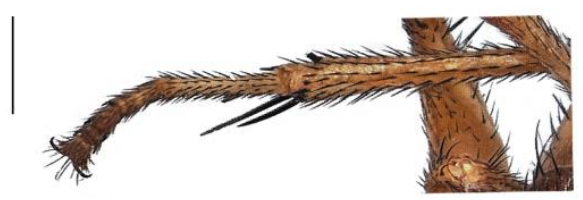

C

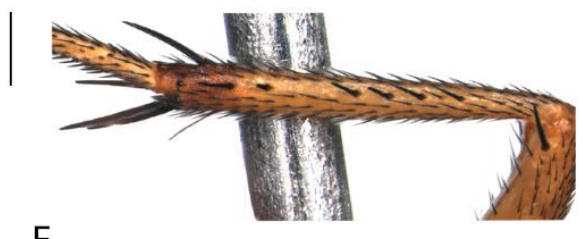

$\mathrm{E}$

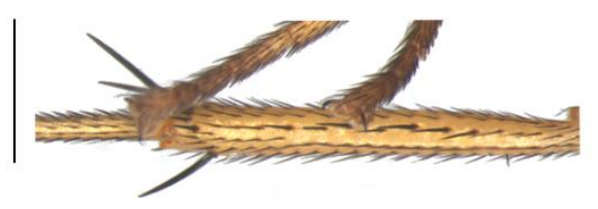

G

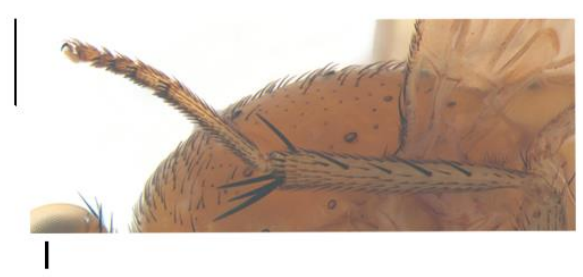

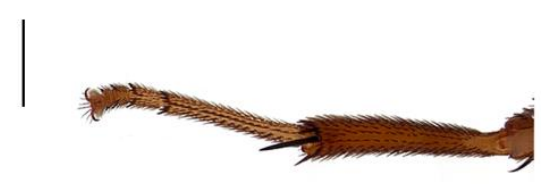

B

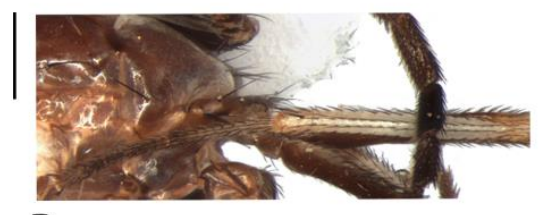

D

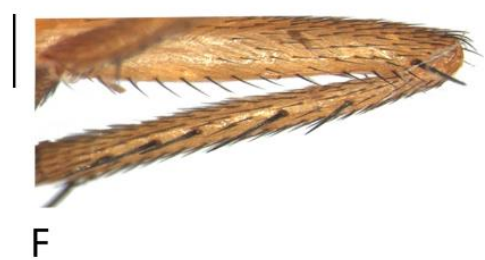

$\mathrm{H}$
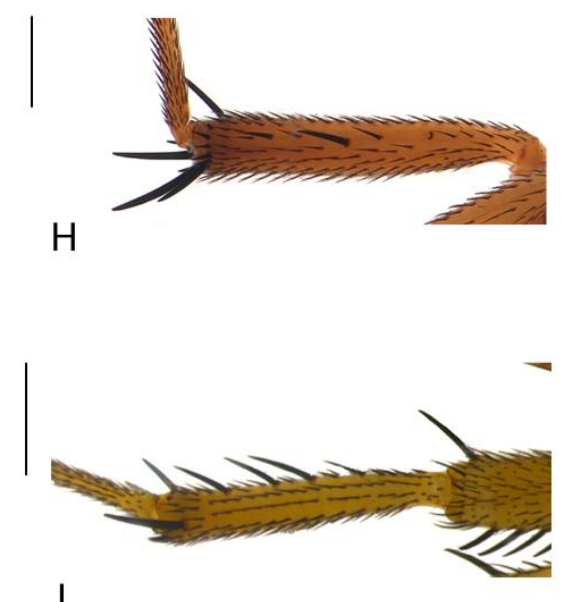

$J$

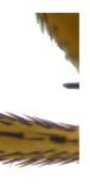

$\mathrm{K}$

Figura 6. Tíbia média, vista dorsolateral. A. Chaetominettia mactans; B. Deutominettia pulchrifrons; C. Griphoneura triangulata; D. Physegeniopsis albeto; E. Allominettia xanthiceps; F. A. geniseta; G. A. approximata; H. A. sp. nov. 1; I. A. sp. nov. 2; J. A. assimilis; K. A. sp. nov. 3. Escala 0,5 mm. 


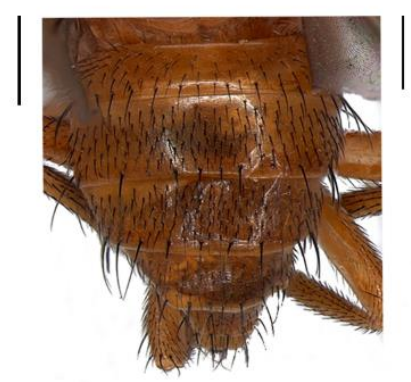

A

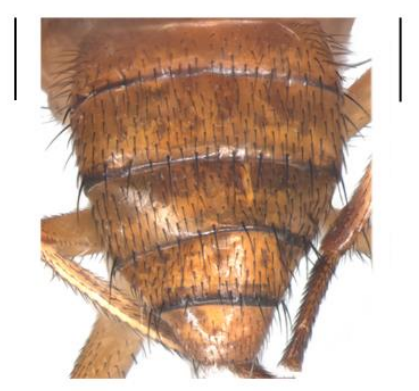

$\mathrm{E}$

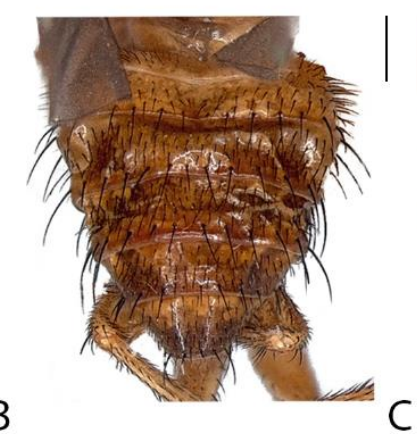

C

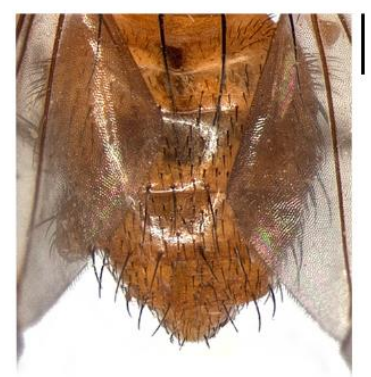

$\mathrm{F}$

G

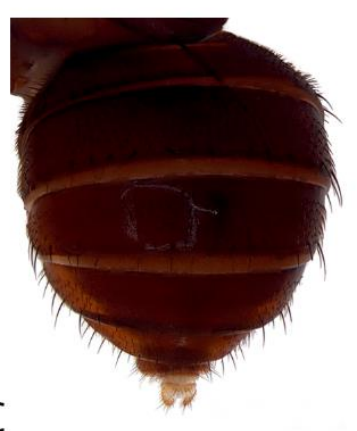

D
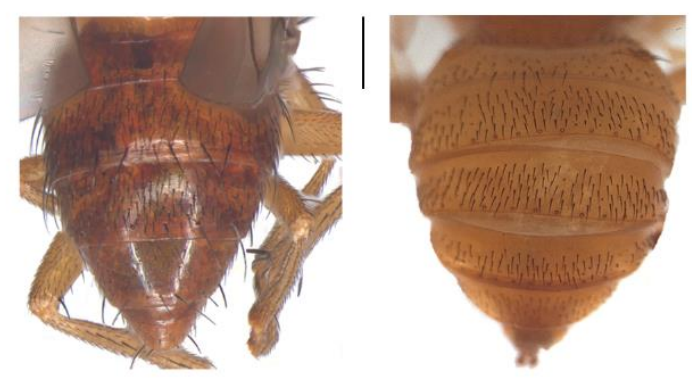

$\mathrm{H}$

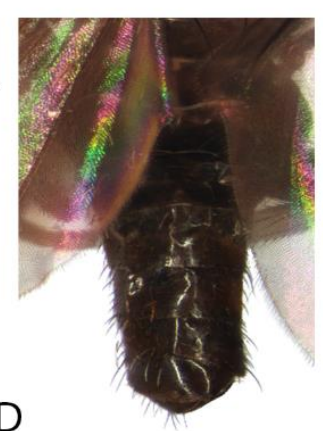

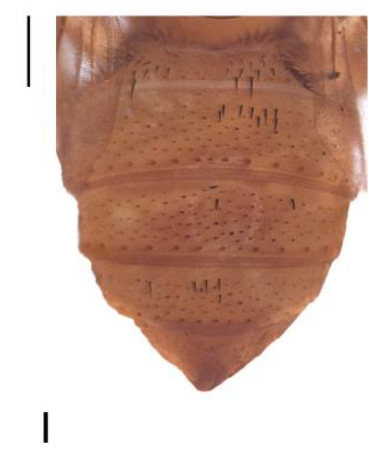
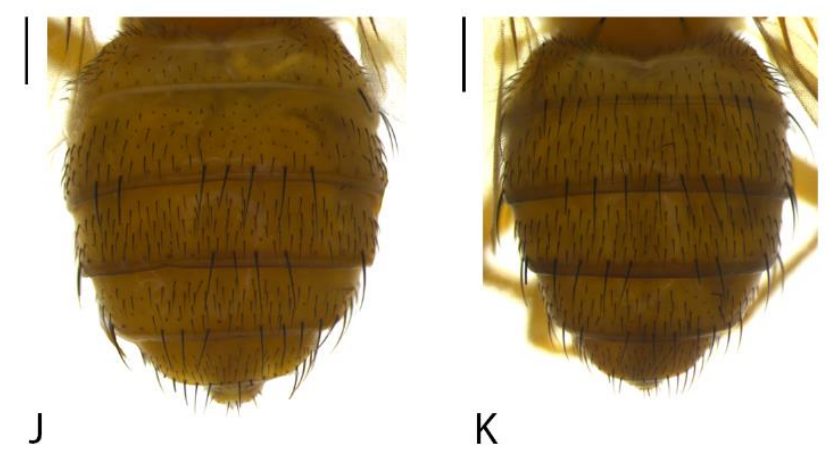

Figura 7. Abdome, vista dorsal. A. Chaetominettia mactans, ô; B. Deutominettia pulchrifrons, $\partial^{\lambda}$; C.

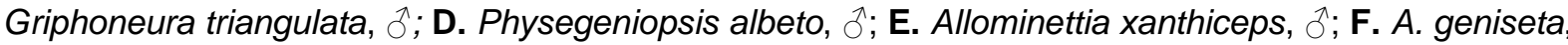

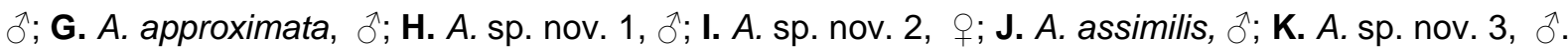
Escala $0,5 \mathrm{~mm}$. 

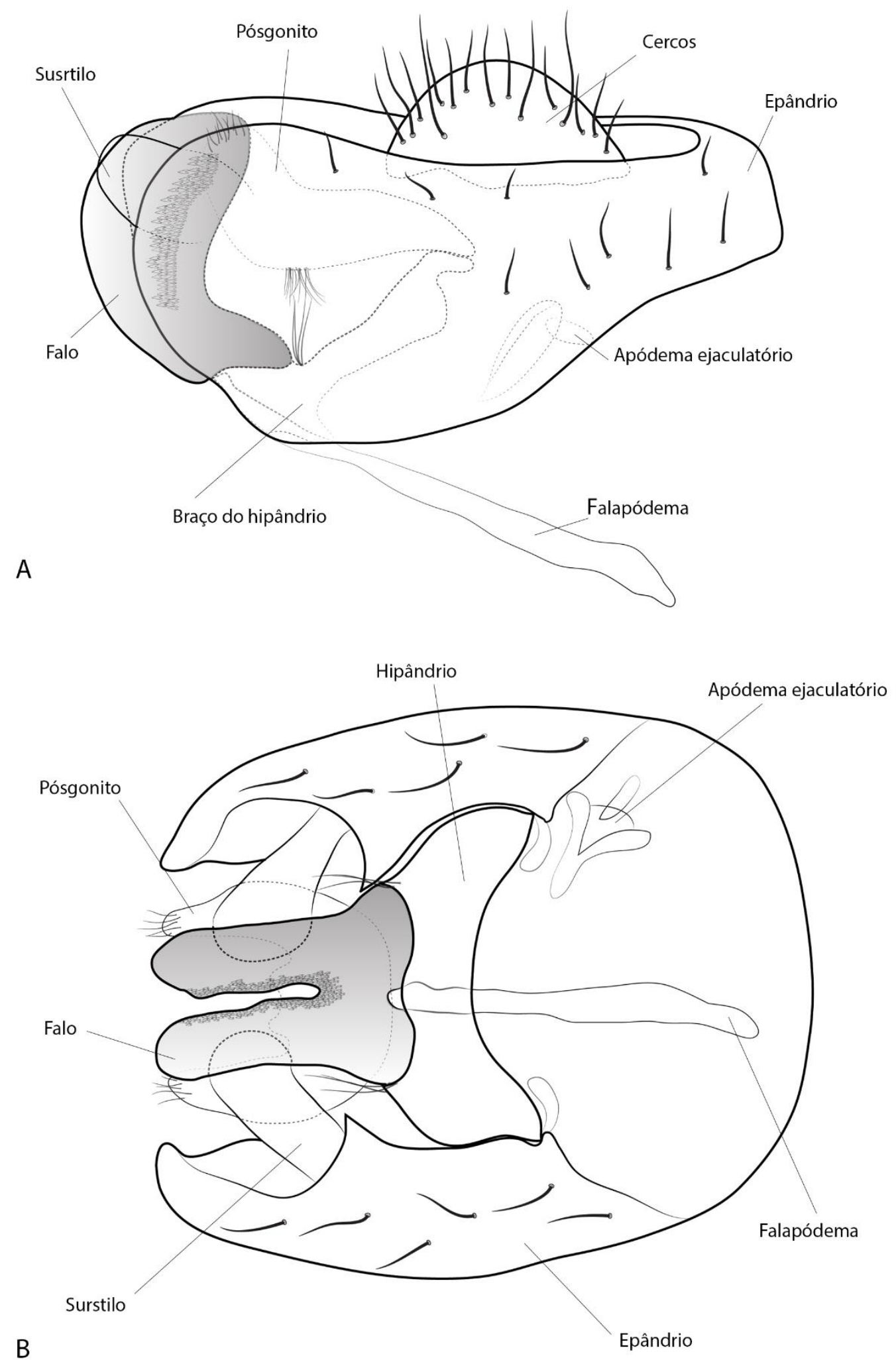

Figura 8. A. xanthiceps, terminália masculina. A. vista lateral; B. vista dorsoventral. Escala $0,5 \mathrm{~mm}$. 


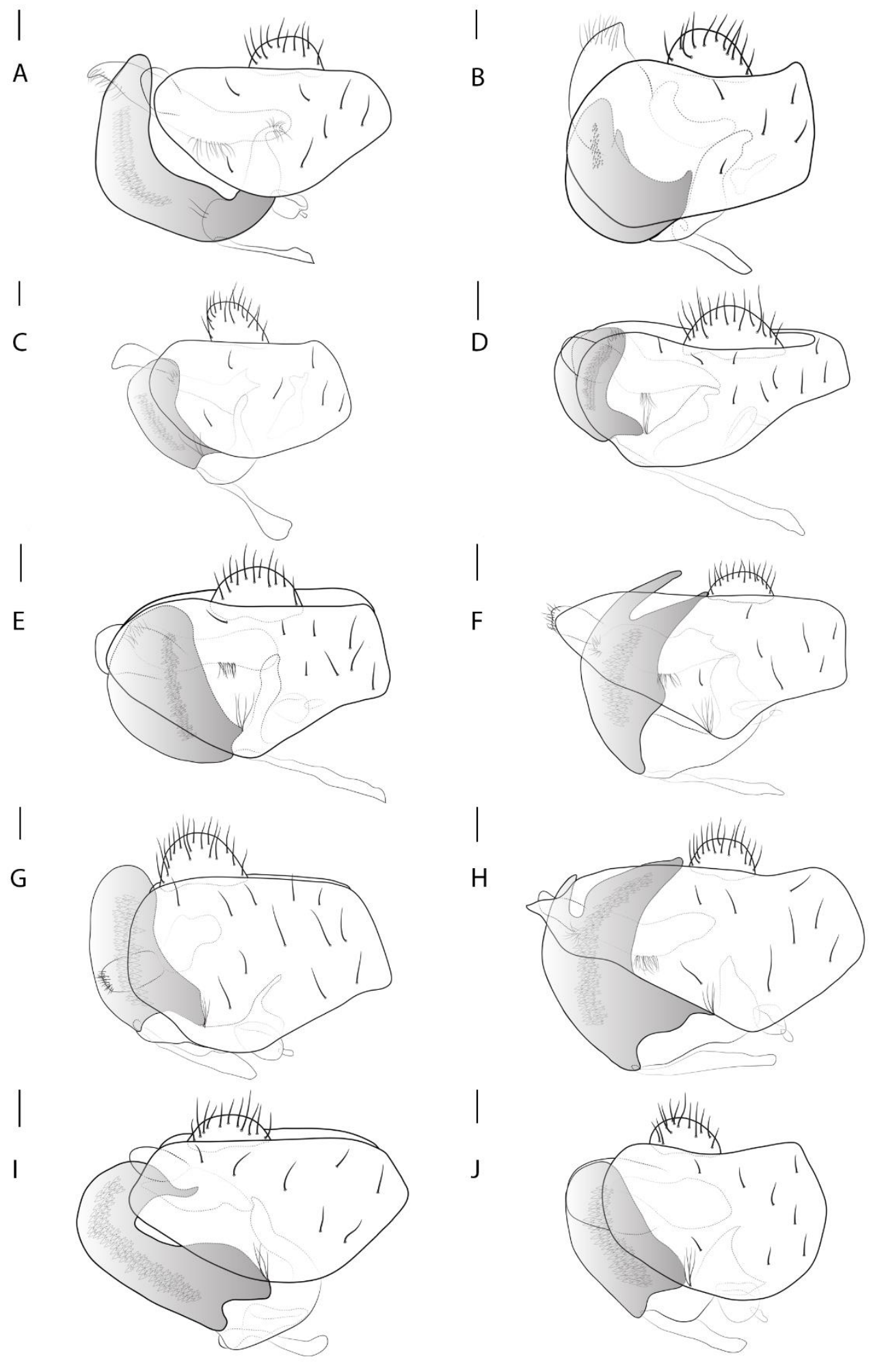

Figura 9. Terminália masculina, vista lateral. A. Chaetominettia mactans; B. Griphoneura triangulata; C. Deutominettia pulchrifrons; D. Allominettia xanthiceps; E. A. geniseta; F. A. approximata; G. A. sp. nov. 1 ; H. A. sp. nov. 2; I. A. assimilis; J. A. sp. nov. 3. Escala $0,5 \mathrm{~mm}$. 


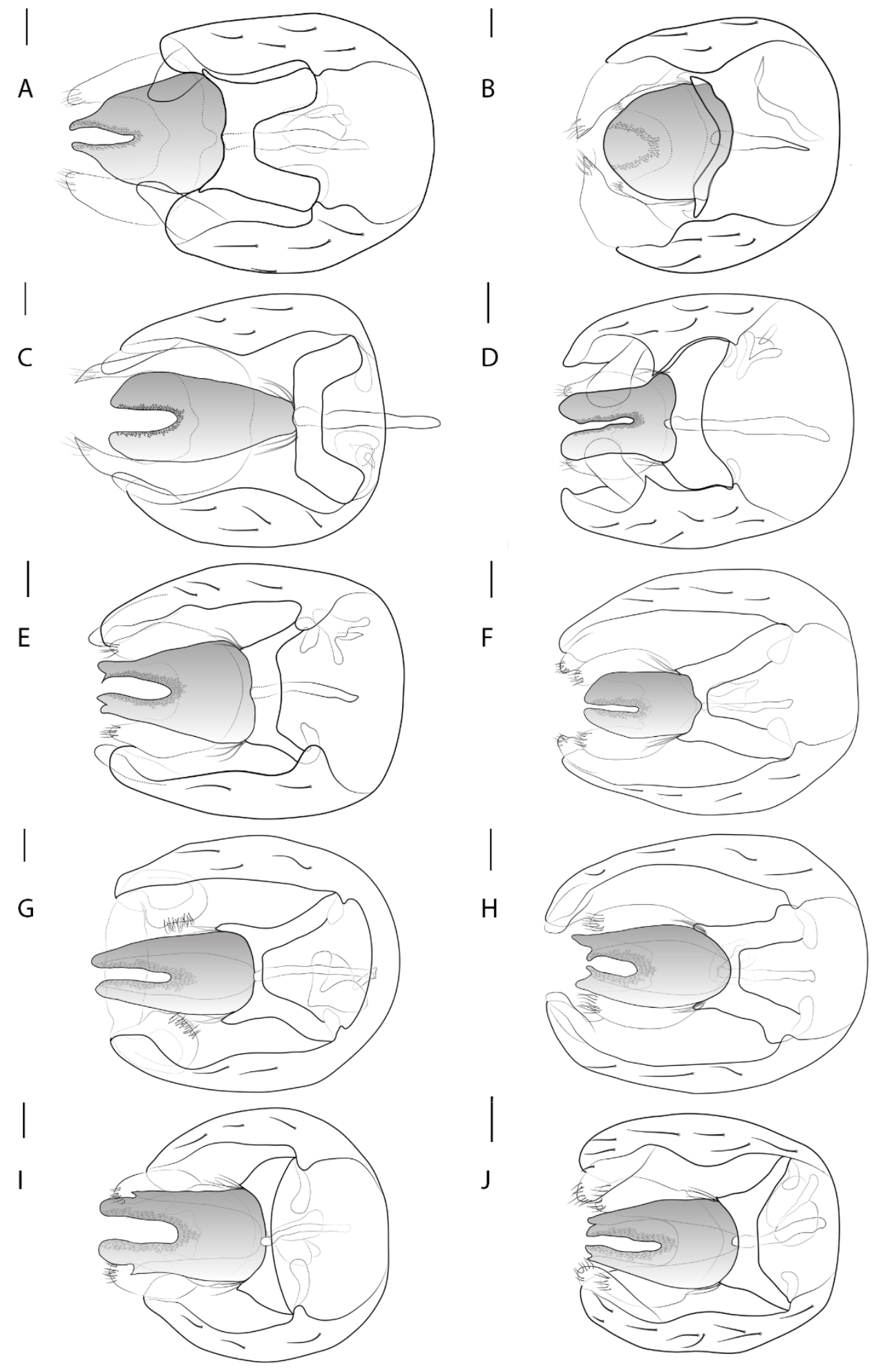

Figura 10. Terminália masculina, vista dorsoventral. A. Chaetominettia mactans; B. Griphoneura triangulata; C. Deutominettia pulchrifrons; D. Allominettia xanthiceps; E. A. geniseta; F. A. approximata; G. A. sp. nov. 1 ; H. A. sp. nov. 2; I. A. assimilis; J. A. sp. nov. 3 . Escala $0,5 \mathrm{~mm}$. 

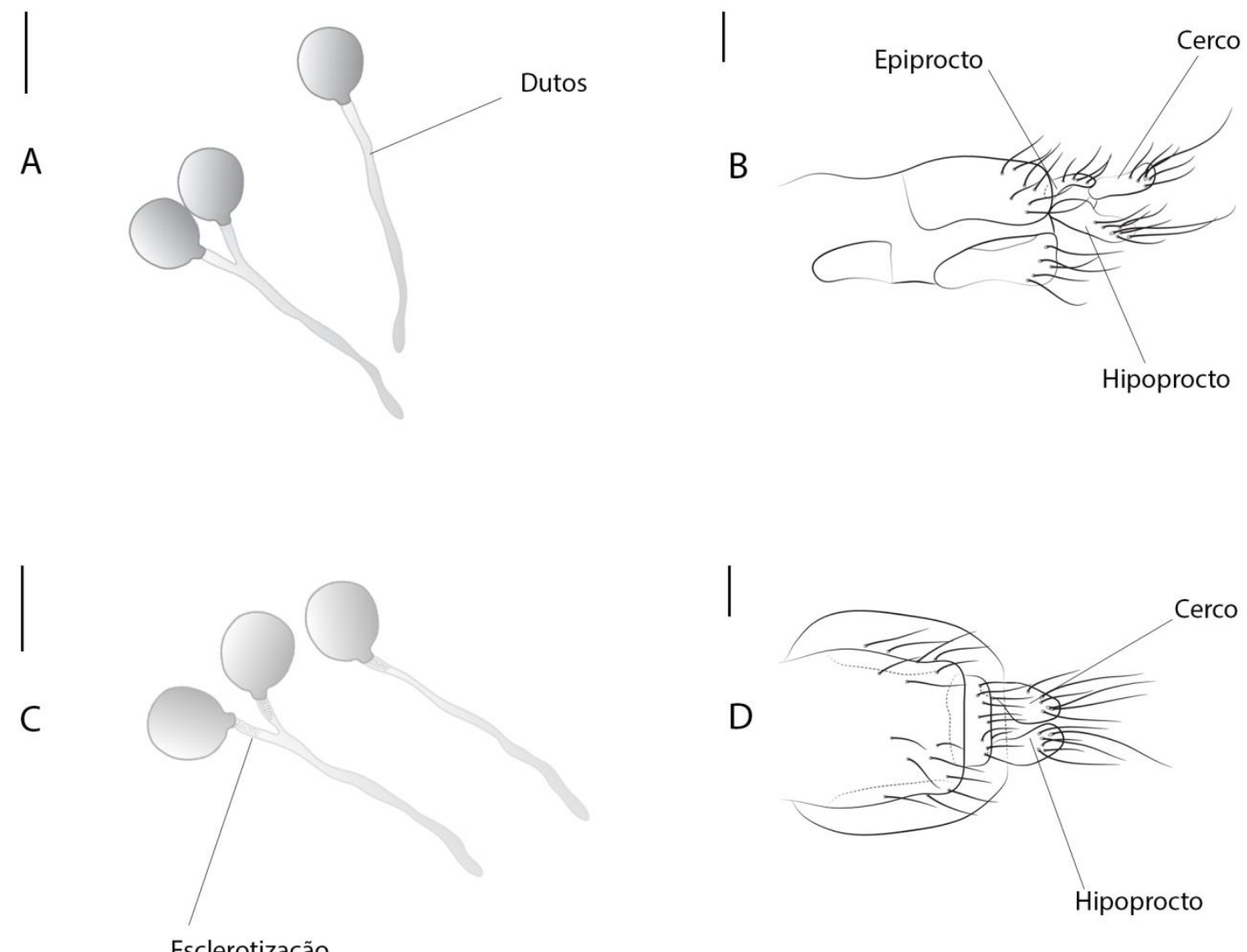

Esclerotização

Figura 11. Pós-abdome da fêmea e espermatecas de espécies de Lauxaniidae. A. Allominettia xanthiceps, espermateca; B. A. xanthiceps, pós-abdome, vista lateral; C. Griphoneura triangulata, espermateca; D. A. geniseta, pós-abdome, vista dorsoventral. Escala 0,5 mm. 

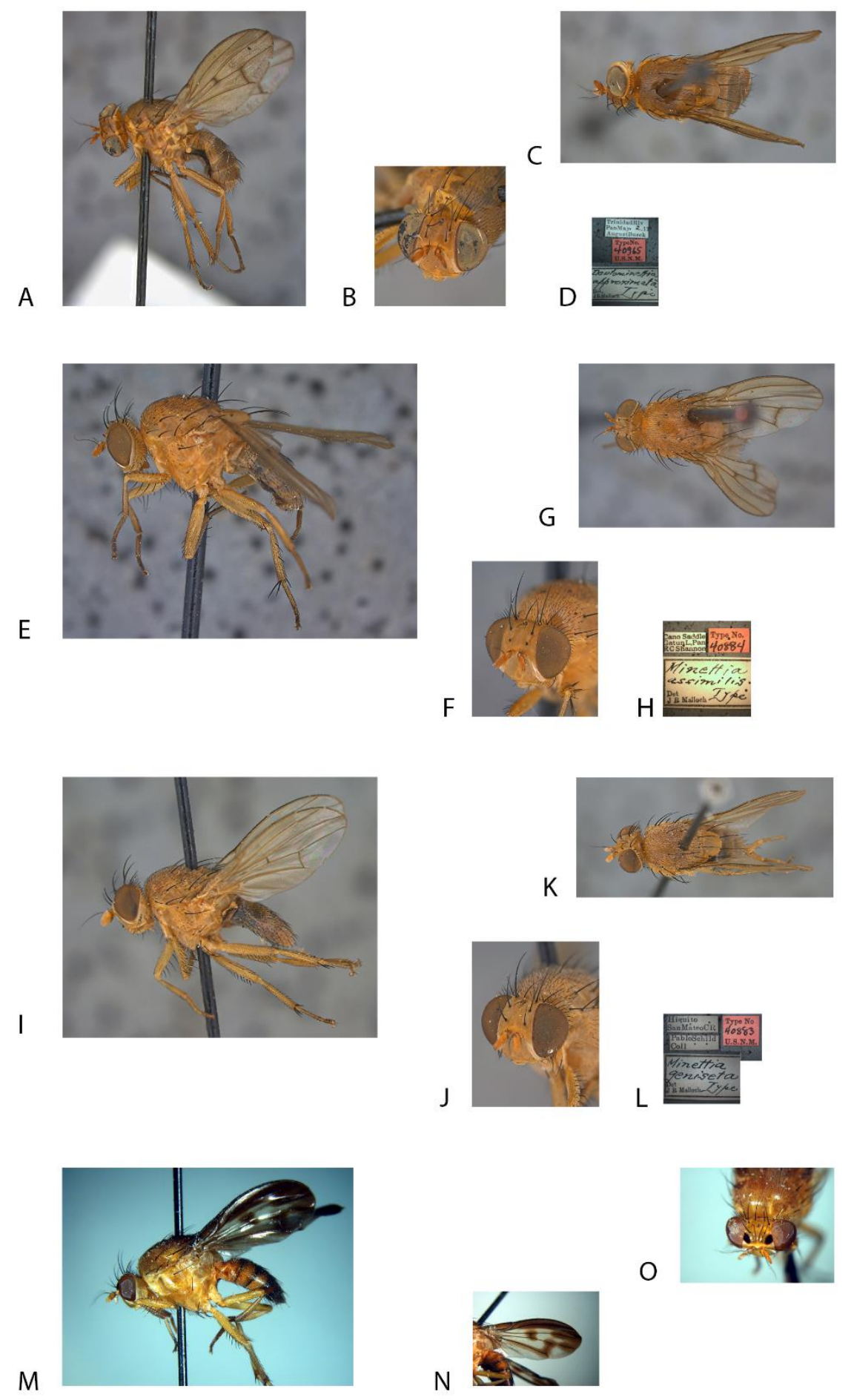

Figura 12. Material tipo das espécies de Allominettia. A - D. A. approximata, holótipo: A., Habitus, vista lateral, B., Cabeça, vista dorsolateral C., Tórax, vista dorsal, D., Dados das etiquetas; E-H. A. assimilis, holótipo: E., Habitus, vista lateral, F., Cabeça, vista dorsolateral, G., Tórax, vista dorsal, H., Dados das etiquetas; I -L. A. geniseta, holótipo: I., Habitus, vista lateral, J., Cabeça, vista dorsolateral, L., Tórax, vista dorsal; M - O. A. xanthiceps, síntipo: M., Habitus, vista lateral, N., Asa, O., Cabeça, vista dorsolateral. 

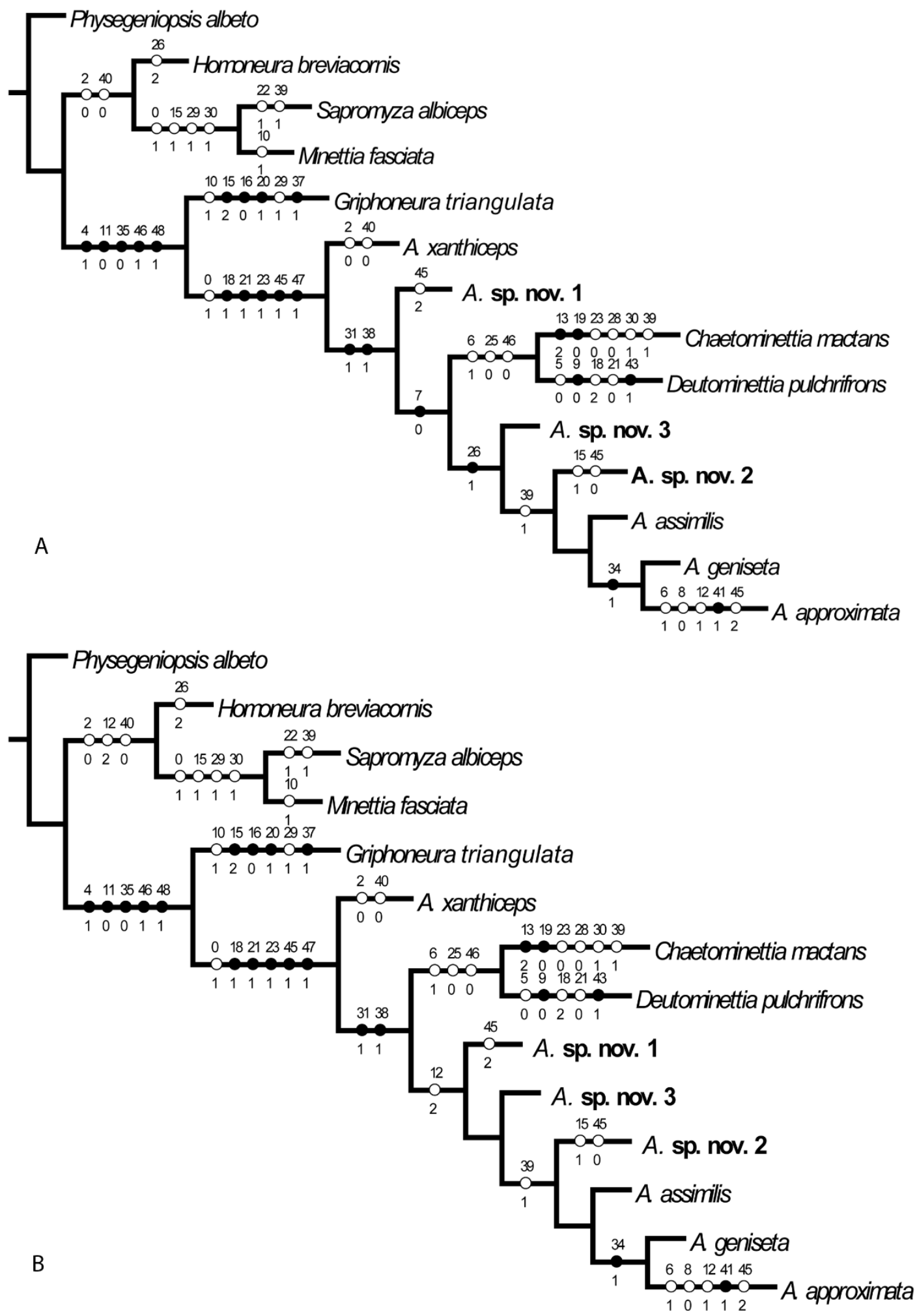

Figura 13. A-B. Árvores com pesagem igual da análise cladística de Allominettia. 

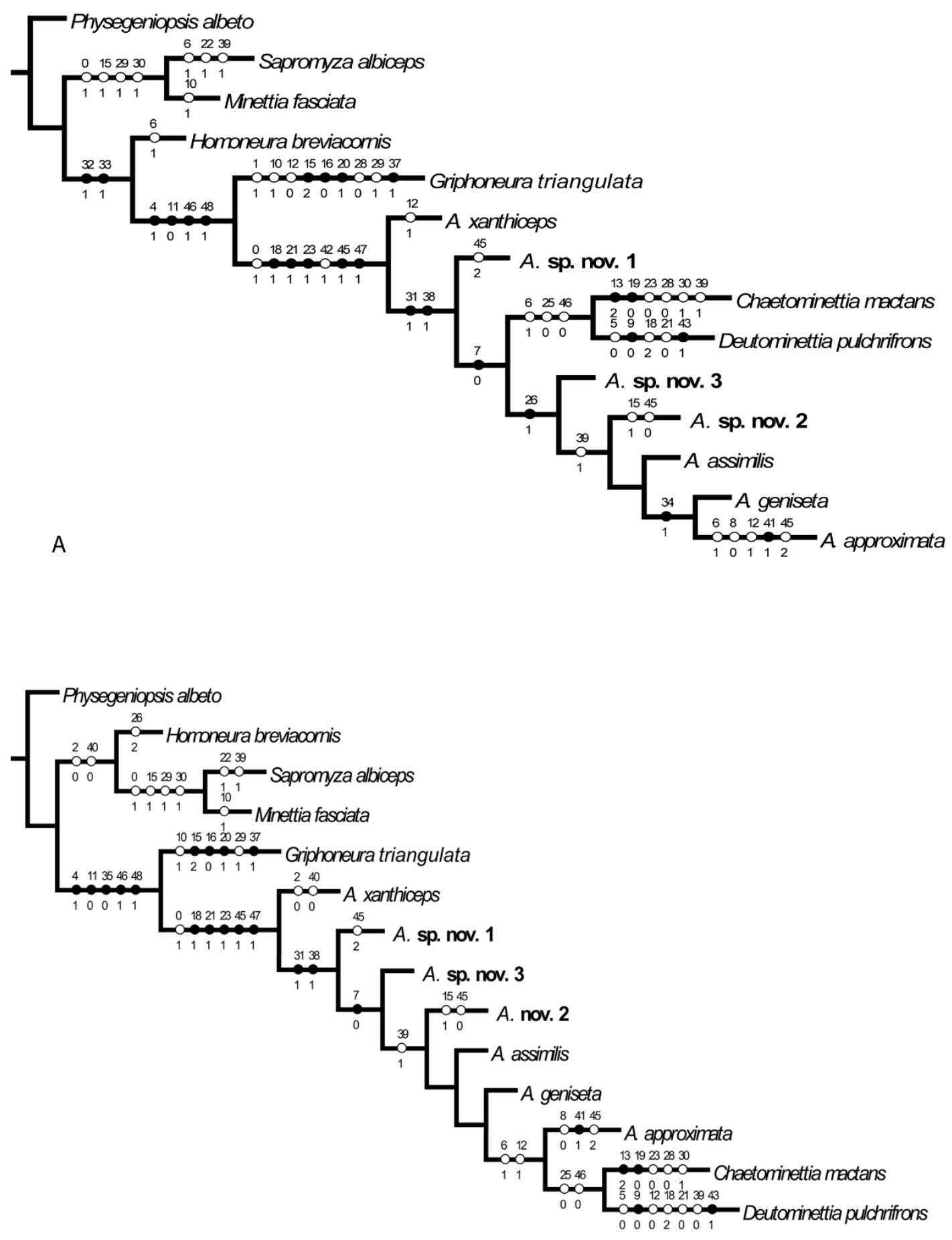

B

Figura 14. A-B. Árvores com pesagem igual da análise cladística de Allominettia. 

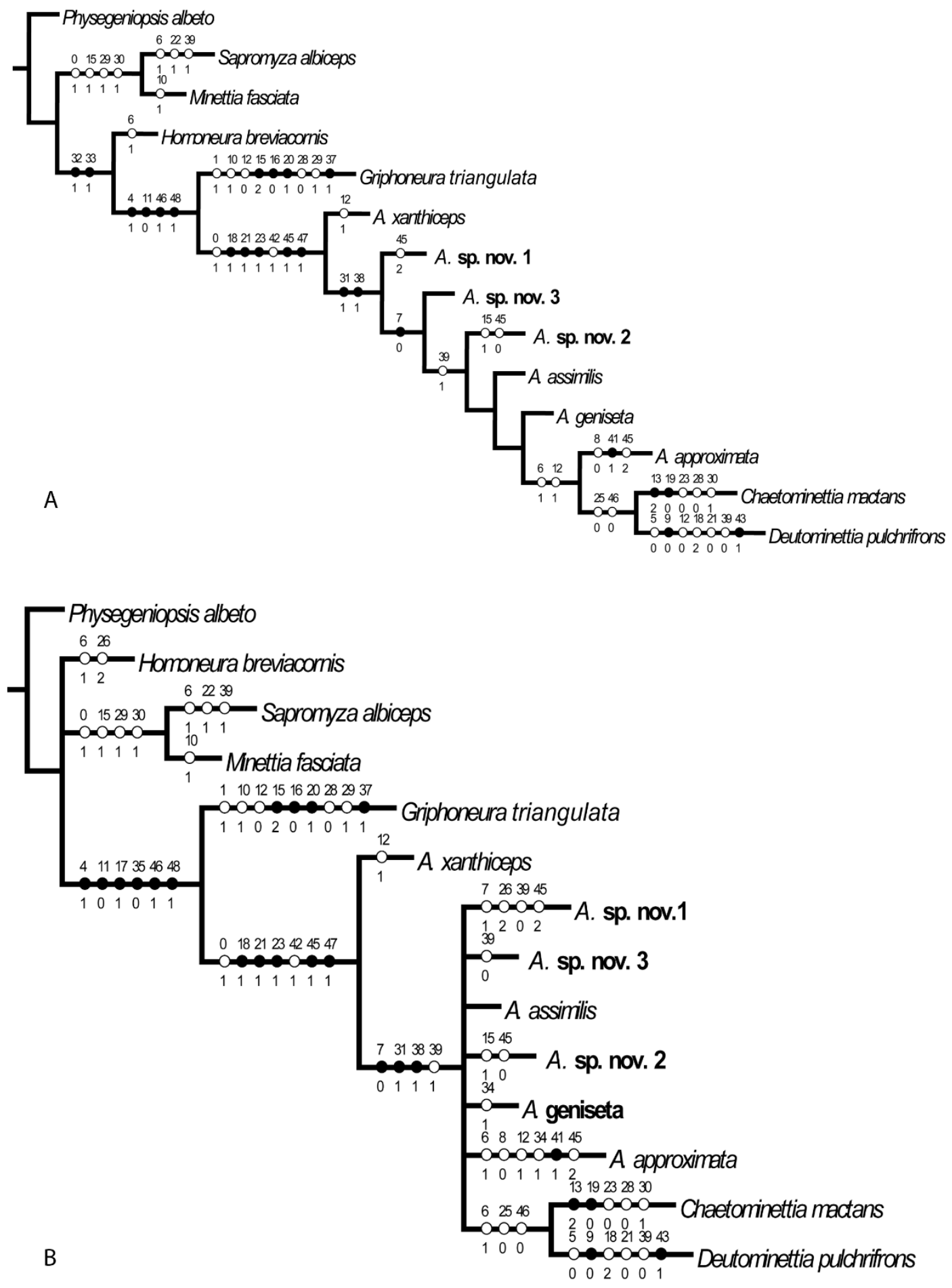

Figura 15. A. Árvore com pesagem igual da análise cladística de Allominettia; B. Consenso das árvores com pesagem igual. 
Tabela 1. Matriz de dados com 49 caracteres e 14 táxons terminais utilizados na análise.

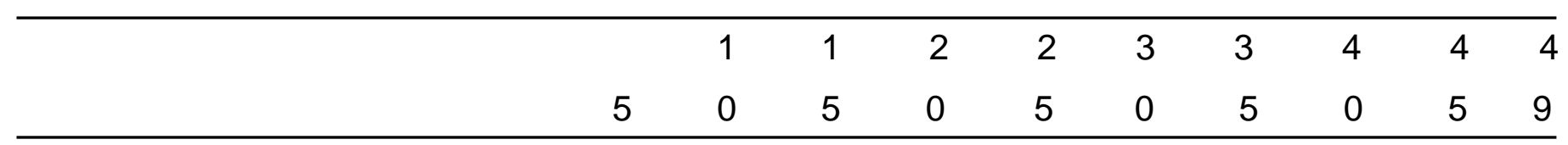

Physegeniopsis albeto

Homoneura breviacornis

Sapromyza albiceps

Minettia fasciata

Griphoneura triangulata

Allominettia xanthiceps

Allominettia sp. nov. 1

Allominettia sp. nov. 3

Allominettia assimilis

Allominettia sp. nov. 2

Allominettia geniseta

Allominettia approximata

Chaetominettia mactans

Deutominettia pulchrifrons
$01110001010100001001000010010000000110 ? ? 101010000$ $0000011111012 ? 1012 ? ? 200 ? ? 0201000110$ ???00 000000000 $1000011111012311122 ? 201011001110$ ??? 10??1 ????? ???? $1000010111112 ? 11 ? 0 ? ? 20000100 ? 11000010000000000000$ 0110110111100112012110100100010011000100100000101 1000110111001110111121210130100011000000001001111 1010110111002110111121210120100111000010101002111 1010110011002110111121210110100111000010101001111 1010110011002110111121210110100111000011101001111 1010110011002111111121210110100111000011101000111 1010110011002110111121210110100111100011101001111 1010111001001110111121210110100111100011111002111 1010111011001210111021200020001111000011101001011 1010101010000110112120210030100111000010101101011 